\title{
Atmospheric HULIS: How humic-like are they? A comprehensive and critical review
}

\author{
E. R. Graber ${ }^{1}$ and Y. Rudich ${ }^{2}$ \\ ${ }^{1}$ Institute of Soil, Water and Environmental Sciences, The Volcani Center, Agricultural Research Organization, Bet Dagan \\ 50250, Israel \\ ${ }^{2}$ Department of Environmental Sciences and Energy Research, The Weizmann Institute of Science, Rehovot 76100, Israel \\ Received: 22 August 2005 - Published in Atmos. Chem. Phys. Discuss.: 11 October 2005 \\ Revised: 11 January 2006 - Accepted: 19 January 2006 - Published: 6 March 2006
}

\begin{abstract}
A class of organic molecules extracted from atmospheric aerosol particles and isolated from fog and cloud water has been termed HUmic-LIke Substances (HULIS) due to a certain resemblance to terrestrial and aquatic humic and fulvic acids. In light of the interest that this class of atmospheric compounds currently attracts, we comprehensively review HULIS properties, as well as laboratory and field investigations concerning their formation and characterization in atmospheric samples. While sharing some important features such as polyacidic nature, accumulating evidence suggests that atmospheric HULIS differ substantially from terrestrial and aquatic humic substances. Major differences between HULIS and humic substances, including smaller average molecular weight, lower aromatic moiety content, greater surface activity, better droplet activation ability, as well as others, are highlighted. Several alternatives are proposed that may explain such differences: (1) the possibility that mono- and di-carboxylic acids and mineral acids abundant in the atmosphere prevent the formation of large humic "supramolecular associations"; (2) that large humic macromolecules are destroyed in the atmosphere by UV radiation, $\mathrm{O}_{3}$, and $\mathrm{OH}^{-}$radicals; 3) that "HULIS" actually consists of a complex, unresolved mixture of relatively small molecules rather than macromolecular entities; and (4) that HULIS formed via abiotic and short-lived oxidative reaction pathways differ substantially from humic substances formed over long time periods via biologically-mediated reactions. It should also be recalled that the vast majority of studies of HULIS relate to the water soluble fraction, which would include only the fulvic acid fraction of humic substances, and exclude the humic acid (base-soluble) and humin (insoluble) fractions of humic substances. A significant effort towards
\end{abstract}

Correspondence to: E. R. Graber

(ergraber@volcani.agri.gov.il) adopting standard extraction and characterization methods is required to develop a better and meaningful comparison between different HULIS samples.

\section{Introduction}

Following reports of macromolecular organic substances in atmospheric aerosol particles and rainwater in the 1980's (Simoneit, 1980; Likens and Galloway, 1983; Mukai and Ambe, 1986), the last decade has witnessed a large increase in studies reporting the prevalence of macromolecular compounds, termed HUmic-LIke Substances (HULIS) in aerosol, fog and cloud water. Interest is fueled by the realization that HULIS may affect aerosol properties, such as their ability to nucleate cloud droplets, or their light absorption. In view of the roles played by humic substances in sorption, complexation and solubilization of pollutant organic molecules in soil and aqueous environments, it is anticipated that HULIS may perform similar functions in atmospheric particles. The realization that HULIS compounds are most likely formed in aerosol particles exemplifies the fact that atmospheric reactions can result in formation of new constituents of higher molecular weight, and not just result in breakdown of parent organic compounds.

HULIS have been so termed because of their apparent similarity to the ubiquitous macromolecular humic substances found in terrestrial and aquatic environments. Conventionally, humic substances are considered to be comprised of naturally occurring, biogenically-derived, heterogeneous organic substances that are yellow to black in color, of high molecular weight, and refractory in nature (Aiken et al., 1985). The exemplifying characteristic of humic substances is that they defy speciation and molecular definition, despite

Published by Copernicus GmbH on behalf of the European Geosciences Union. 
the application of a multiplicity of characterization methods. The purpose of this paper is to review the considerable information that has accumulated thus far concerning atmospheric HULIS, with an eye towards defining the current state of the art. Some of the material covered in this review has been recently addressed by Gelencser (2004). Here, however, we have made a special effort to comprehensively and critically review the vast majority of available studies to date, and to synthesize their findings with comparison to each other and to topical results from the applicable literature on humic substances from terrestrial and aquatic environments. There is a special emphasis on methods for humic substances and HULIS extraction and purification, HULIS characterization and properties, and on laboratory experiments that have identified possible pathways for HULIS formation. Based on the accumulated information, it is suggested that atmospheric HULIS, while similar in some respects to humic substances (e.g., polyacidity), also differ in certain important ways (e.g., surface activity, droplet activation efficiency) from terrestrial and aquatic humic and fulvic acids.

\section{Pioneering studies}

One of the earliest reports of humic-like compounds in aerosol particles was a study of aeolian dust by Simoneit (1980), where $\mathrm{H} / \mathrm{C}$ ratio and $\delta^{13} \mathrm{C}$ values were used to construe a terrestrial soil origin, corresponding to the actual origin of the dust particles. In a later study of rural aerosol from Japan, humic substances were found to represent between 1 to $6 \%$ of the total organic carbon fraction (Mukai and Ambe, 1986). By means of infrared and UV-VIS spectroscopic investigations and elemental composition fingerprinting, it was determined that the humic acid extracts were most similar to extracts from biomass burning smoke particles (Mukai and Ambe 1986). These authors also suggested that aerosolderived humic substances consisted of polycyclic ring structures with hydrocarbon side chains, and hydroxyl, carboxyl and carbonyl groups. This general chemical structure for atmospheric HULIS determined about 20 years ago still represents the current consensus, after the application of scores of different analytical techniques.

Also in the early 1980s, dissolved phase macromolecular organic carbon in rural rainwater was fractionated by ultrafiltration techniques and chemically characterized (Likens and Galloway, 1983). The macromolecular portion (>1000 nominal molecular weight cutoff; NMWCO) accounted for some $35-43 \%$ of the total organic carbon (TOC), with carbohydrates, tannins/lignins, and organic nitrogen $(\mathrm{N})$ being important constituents. Based on these chemical attributes, degradation and dissolution of plant structural material was hypothesized to be the source of the macromolecular fraction (Likens and Galloway, 1983). Thus, even in such earlier years of study, a multiplicity of sources for macromolecular organic substances in aerosol was recognized: terrestrial (Si- moneit, 1980), biomass burning (Mukai and Ambe, 1986), and plant degradation products (Likens and Galloway, 1983).

Following these pioneering works, the study of macromolecular substances in the atmosphere suffered a hiatus for more than ten years, until the work of Havers et al. (1998), wherein the term HULIS, an abbreviation for HUmic-LIke Substances, was coined. Examining a standard reference air dust as well as airborne particulate matter, Havers et al. (1998) attributed $10 \%$ or more of aerosol organic carbon to macromolecular substances similar to humic and fulvic acids. The humic materials, extracted by alkaline aqueous solution and isolated by ion exchange, were characterized by molecular size distribution, carbon content, and UV-VIS, Fourier transform infrared (FTIR) and nuclear magnetic resonance $\left({ }^{1} \mathrm{H}-\mathrm{NMR}\right)$ spectra. Since these early efforts, many different methods have been employed in attempts to speciate HULIS and characterize their essential qualities.

\section{Extraction and isolation of HULIS}

One of the major differences between the pioneering studies and those undertaken since then has been in HULIS extraction methodology. The earlier works (Simoneit 1980; Mukai and Ambe 1986) studied base-extracted and acid-precipitated material, the exact parallel to humic acids from soil systems. The more recent studies have focused mainly on the water soluble organic carbon (WSOC) fraction, which, by definition will contain compounds more similar to fulvic acid than humic acid, and which may also include many low molecular weight organic and inorganic species. Because extraction and isolation methodologies can be expected to affect substantially the chemical and physical nature of the studied material, we review the traditional methods used for humic substances in terrestrial and aquatic environments, and those developed for atmospheric HULIS research.

\subsection{Terrestrial/aquatic humic substances}

Humic substances are subdivided into three operationallydefined fractions: fulvic acid (water soluble at all $\mathrm{pHs}$ ); humic acid (base soluble, acid ( $\mathrm{pH}$ 1) insoluble); and humin (insoluble at all $\mathrm{pHs}$ ). In soil and aquatic sciences, nonionic macroporous copolymer sorbents with large surface area such as the Amberlite XAD resin series (2, 4 and 8) are widely employed for isolation and concentration of different organic matter fractions because of their high sorption capacity and ease of elution (Aiken et al., 1979; Thurman and Malcolm, 1979; Leenheer, 1981; Thurman and Malcolm, 1981; Aiken et al., 1992). XAD-2 and XAD4 resins are composed of a very hydrophobic polystyrenedivinylbenzene copolymer, possess no ion-exchange capacity, are neutral at all $\mathrm{pHs}$ and exhibit certain size exclusion behavior for larger macromolecules (Aiken et al., 1979; Aiken, 1985). XAD-8 resin is composed of a non-aromatic 
polymethylmethacrylate ester which is ionized at high $\mathrm{pHs}$ (Aiken et al., 1979; Aiken, 1985). XAD-8 wets more easily, absorbs more water, exhibits faster sorption kinetics, has higher sorption capacity, and is more efficiently eluted than the styrene-divinylbenzene (XAD-2,-4) resins, particularly for fulvic acids (Aiken et al., 1979). The principal driving force for sorption on XAD-8 resin is physical adsorption, i.e., van der Waals forces. At low $\mathrm{pH}$, protonated weak organic acids, including humic substances, adsorb on the resin; at high $\mathrm{pH}$, ionized weak organic acids easily desorb from the resin (98\% efficiency at $\mathrm{pH} 13$; Aiken et al., 1979). XAD8 has been widely employed by the International Humics Substances Society (IHSS) for isolation of humic and fulvic acids from different matrices (www.ihss.gatech.edu).

Different specific protocols for separation of aqueous organic matter into fractions based on their polarity (hydrophobic/hydrophilic), acid/neutral/base properties, or compound class characteristics can be found in several studies (Thurman and Malcolm, 1979; Leenheer, 1981; Thurman and Malcolm, 1981; Aiken et al., 1992; Leenheer et al., 2000; Croue, 2004). These protocols generally involve initial separation at low $\mathrm{pH}$ on $\mathrm{XAD}-8$, elution in $\mathrm{NaOH}$, followed either by separations on ion exchange resins (e.g., anion exchange and/or cation exchange), or on other non-ionic macromolecular resins (e.g., XAD-4; Fig. 1). The fractions separated by these methods are operationally defined. However, low molecular weight acids can also adsorb to XAD resins, depending on their acidity, resin polarity, and the ratio of resin to aqueous sample volume (Thurman et al., 1978; Thurman and Malcolm, 1979; Leenheer, 1981; Thurman and Malcolm, 1981; Aiken et al., 1992). With this caveat in mind, characteristically, the fulvic and humic acid fractions (often termed hydrophobic acid fraction) is considered to make up the fraction sorbed at low $\mathrm{pH}$ on XAD-8 and eluted at high pH. This fraction may also contain aliphatic carboxylic acids, and one and two-ring phenols (Aiken et al., 1992).

Concentration of organic acids from water, including fulvic acids, may be also accomplished by adsorption onto a weak anion exchange resin (such as diethylaminoethylcellulose; DEAE-cellulose (Miles et al., 1983; Aiken, 1985; Pettersson et al., 1994), with salts being removed separately by purification of the concentrate on an XAD resin (Pettersson et al., 1994). The concentrate can be further fractionated into hydrophilic and hydrophobic acids, for example, by tandem XAD-8 and XAD-4 columns. DEAE-cellulose has a lower adsorption capacity than XAD-8, and isolates a much smaller fraction of total dissolved organic matter (Pettersson and Rahm, 1996).

The IHSS (www.ihss.gatech.edu) has established a collection of standard and reference humic substances that makes it possible for researchers to compare critically their experimental results on humic materials derived from terrestrial and aquatic sources. All materials originated from carefully chosen and specified locations, samples were isolated by fully documented, controlled and supervised proce-

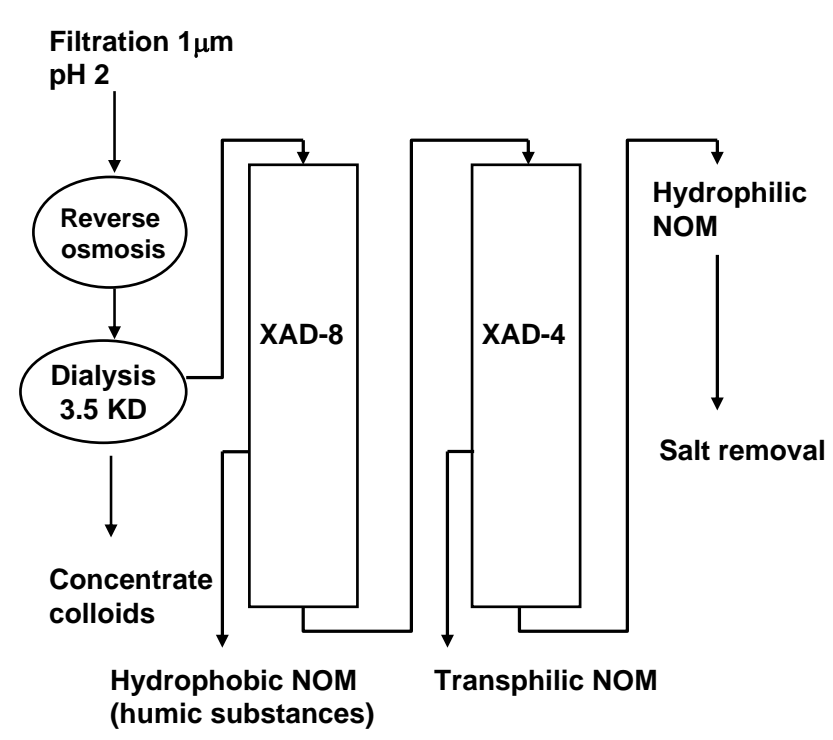

Fig. 1. Example of a comprehensive isolation scheme for aqueous organic matter (NOM). After Croue (2004; with permission).

dures, all materials were thoroughly homogenized, and the bulk solids are available to enable comparison of different extraction methods. The standard humic and fulvic acids have been well-characterized in terms of elemental composition, acid functional group analysis, amino acid and carbohydrate content, ${ }^{13} \mathrm{C}$-NMR estimates of carbon distribution, and ${ }^{13} \mathrm{C}$-NMR, FTIR and fluorescence spectra. Humic materials available from commercial suppliers such as Fluka and Aldrich can be more problematic, as they have high and batch-variable ash contents (Malcolm and MacCarthy, 1986; Chin et al., 1994; Hur and Schlautman, 2003). Compared to soil and aquatic humic and fulvic acids, the ${ }^{13} \mathrm{C}-\mathrm{NMR}$ spectra of commercial materials indicate lower carboxyl content, higher saturated aliphatic carbon content, and lower aromatic carbon content (Malcolm and MacCarthy, 1986). The commercial products also have relatively high average molecular weights; for example, MW estimates for Aldrich humic acid vary from about 4000 to more than $14000 \mathrm{Da}$ (Beckett et al., 1987; Chin et al., 1994; Hur and Schlautman, 2003).

\subsection{Atmospheric HULIS}

Several studies of atmospheric samples have employed an aqueous alkali extraction similar to standard procedures for extraction of humic and fulvic acids from soils (Simoneit, 1980; Mukai and Ambe, 1986; Havers et al., 1998; Subbalakshmi et al., 2000). The base-extract contained humic and fulvic acids, low molecular weight organic acids, hydrophobic neutral compounds, and salts. The humic acid fraction was then isolated by precipitation in acid, and separated from salts by gel permeation chromatography (Mukai and Ambe 1986) or by dialysis (Subbalakshmi et al., 2000). In Havers et al. (1998), the neutralized alkali extract was concentrated 
on a DEAE-cellulose (weakly basic resin), eluted in strong $\mathrm{NaOH}$, and converted to $\mathrm{H}^{+}$-form on a cation exchange resin, removing inorganic salts. The final isolate thus contained undifferentiated humic and fulvic acids, and low molecular weight (LMW) organic acids.

Andracchio et al. (2002) developed an isolation protocol by which synthetic mixtures of low molecular weight (LMW) organic compounds (mainly mono-, di-, and tricarboxylic acids), humic acid standards, and fulvic acid standards were separated into three fractions on an Amberlite XAD-2 resin. The smallest acids (oxalic, acetic, and formic) and inorganic salts were eluted by weak $\mathrm{HCl}$ in the 1 st fraction (Andracchio et al., 2002). All other LMW test compounds (hydrophilic organic acids) and tannic acid were eluted by methanol into the 2nd fraction. About 20 to $25 \%$ of the standard humic, and $30-35 \%$ of the standard fulvic acids, also eluted into the 2 nd fraction. The remainder of the humic substances was eluted into the 3rd fraction by a basic $\mathrm{NH}_{3}$ solution. The portion of humic substances eluted in the 2nd fraction presumably consists of lower MW and/or more hydrophilic components.

Size exclusion chromatography (SEC) with UV-VIS detection of synthetic mixtures showed differences between the three fractions (Andracchio et al., 2002). Fractionated fog, interstitial aerosol, and cloud samples also demonstrated a retention time difference for the three fractions, but with considerably more overlap between the 2 nd and 3rd fractions than for the synthetic mixtures. In fog samples, between $12-22 \%$ of the total WSOC eluted in the 3rd fraction, which presumably represents the most hydrophobic and largest WSOC-HULIS components. Since atmosphericprevalent HULIS are expected to be dominated by relatively more hydrophilic, more acidic, and lower MW components than the standard materials employed in development of the method, it may be anticipated that a significant fraction of HULIS will elute in the 2nd fraction, and will not be differentiated from other small, well-defined organic and inorganic species present in atmospheric samples. It should be noted that $\mathrm{NH}_{4}^{+}$can interact strongly with humic substances, and may be difficult to eliminate from the final product, possibly leading to undesired changes in physical-chemical characteristics of the isolate (Stevenson 1982).

Varga et al. (2001) tested the isolation of water-soluble organic matter from atmospheric aerosol on various $\mathrm{C} 18$ solid phase extraction (SPE) packings and on a polymer-based Oasis HLB SPE packing. Their optimized method involved acidifying the water extract to $\mathrm{pH} 2$ and applying it to an Oasis HLB SPE cartridge (Waters Inc.), followed by elution in methanol $(\mathrm{MeOH})$. Inorganic components passed into the effluent, along with about $40 \%$ of the total WSOC in the sample. The remaining $60 \%$ of WSOC, desorbed from the SPE cartridge in $\mathrm{MeOH}$, contained more than $90 \%$ of the fluorescence and about $70 \%$ of the UV activity of the total WSOC fraction. Unfortunately, the method was not validated with model LMW organic acids, fulvic acids or other humic sub- stances, so the distribution of hydrophilic/hydrophobic acids in the different fractions is unknown. Varga et al. (2001) also tested a two step separation method involving sorption of aerosol-extracted WSOC onto C18 stationary phases in tandem at different $\mathrm{pH}$ values. In this method, about $25 \%$ of the WSOC passed directly into the column effluent, while another $15 \%$ was absorbed irreversibly on the cartridges. According to Krivacsy et al. (2001a) who used the two cartridge method, a standard FA was fractionated in the same proportions on the two cartridges as aerosol WSOC.

Recently, Limbeck et al. (2005) developed a method for carbon-specific determination of humic substances based on a two-step isolation procedure involving separation on a C18 SPE phase, followed by isolation on a strong anion exchanger. The isolation step was followed by on-line detection of the carbon, with a minimum detection limit of about $8 \mu \mathrm{g}$. Like Varga et al. (2001), they reported about 25\% irreversible sorption on the SPE cartridge.

Decesari et al. (2000) exploited the acidic nature of HULIS compounds to separate aerosol WSOC into fractions by preparative ion exchange chromatography, whereby deprotonated carboxylic acids were separated at alkaline $\mathrm{pH}$ using a weak anion exchanger (DEAE) stationary phase. By gradually increasing the ionic strength of the eluent buffer, inorganic and organic anionic species with increasing charges per molecule eluted sequentially and were detected at $254 \mathrm{~nm}$. In this way, the authors fractionated WSOC into (i) neutral and/or basic compounds; (ii) compounds containing one or two charges per molecule, usually mono- and di-carboxylic acids; and (iii) polyacidic compounds, with at least three negative charges per molecule. Nitrate, the only inorganic anionic species with significant absorbance at $254 \mathrm{~nm}$, elutes in the second fraction. The overall WSOC recovery was about $77 \%$, with the polyacidic fraction (iii) representing about $17 \%$, mono- and di-carboxylic acid fraction (ii) about $35 \%$, and neutral/basic compound fraction (i) about $25 \%$ of WSOC, respectively. The IHSS Suwannee River Fulvic Acid (SRFA) reference material had a similar retention time and peak shape as the third, polyacidic fraction. A drawback to this method is that salts are not removed.

Duarte et al. (2004) applied an acidified WSOC aerosol particle extract to tandem XAD-8 and XAD-4 resin columns, similar to the method developed by Aiken et al. (1992), but employing an eluant comprised of 2:3 solution of $\mathrm{MeOH}$ :water instead of a basic aqueous solution which has, in the past, been found to be the most efficient eluant for fulvic and humic acids from XAD resins (Aiken et al. 1979). Recoveries from XAD- 8 and XAD-4 in the $\mathrm{MeOH}$ :water eluant represented $60 \%$ and $9 \%$ respectively of the total WSOC (Duarte et al. 2004). In other isolation schemes, $\mathrm{MeOH}$ has been employed to elute neutral hydrophobic compounds from XAD-8 after fulvic acids were eluted in a basic $\mathrm{NaOH}$ solution (Thurman and Malcolm 1979; Leenheer 1981). Considering this, the isolate obtained via the method of Duarte et al. (2004) may contain neutral hydrophobic 
compounds in addition to HULIS. Following more closely the method developed by the IHSS for fulvic and humic acid extraction from solid materials (www.ihss.gatech.edu), Dinar et al. (2006) extracted HULIS from aerosol particles collected on glass-fiber filters by consecutive water and waterbase extractions. HULIS was separated from other water soluble and base-soluble aerosol organic and inorganic species by adsorption onto an intensively pre-cleaned XAD-8 resin, followed by elution in a basic solution. The eluant was cation-exchanged on an $\mathrm{H}^{+}$-saturated cation-exchange resin to produce protonated acids. XAD-8 resin separation of hydrophobic (HULIS) and hydrophilic components of WSOC was also employed by Sannigrahi et al. (2005), without a subsequent cation-exchange procedure.

Unfortunately, inter-comparison between these different methods has not been conducted, and, in certain cases, the methods have not been validated with mixtures of LMW compounds and humic substances. Hence it is difficult to evaluate whether the different methods actually isolate and extract the same or comparable organic fractions, and whether the isolated fractions can be strictly compared to humic or fulvic acids. A more rigorous approach to the extraction and isolation of atmospheric HULIS is definitely warranted. The lack of a consistent approach to obtaining an operational definition for aerosol-associated HULIS almost certainly hampers the study of this component.

\section{Spectroscopic characterization of HULIS}

Extraction of useful chemical structural information from spectroscopic methods applied to complex multicomponent mixtures such as humic substances or WSOC from atmospheric samples is a non-trivial proposition. This is because measured spectroscopic signals represent the superposition of signals from the individual components of the mixture. As such, similar spectroscopic results do not necessarily imply similar compositions or structures.

\subsection{UV-VIS Spectroscopy}

A number of studies have measured UV-VIS spectra for isolated HULIS or bulk WSOC derived from aerosol, fog, or cloud for the purpose of comparing results to spectra obtained for humic or fulvic acids (Krivacsy et al., 1997; Havers et al., 1998; Zappoli et al., 1999; Krivacsy et al., 2000; Kiss et al., 2001; Krivacsy et al., 2001a; Varga et al., 2001; Kiss et al., 2002; Duarte et al., 2005). The resultant spectra have been featureless, with increasing absorptivity towards shorter wavelengths. In this regard, such spectra are similar to typical UV-VIS spectra of humic substances, and thus have been considered to provide some sort of evidence that HULIS is similar in chemical structure to humic substances, and also to demonstrate the presence of conjugated double bond systems (continuous absorption up to about $400 \mathrm{~nm}$ ). Com- monly however, the spectra obtained for HULIS display relatively more absorbance in shorter wavelength regions, and less in the longer wavelength regions as compared with terrestrial and aquatic humic substances. Therefore, considering that both atmospheric samples and humic substances consist of heterogeneous complex mixtures of many chemical components, each of which may contain a variety of chromophores and those possibly at differing absorptivities, conclusions about HULIS similarity to humic substances on the basis of UV-VIS spectra should be made with caution. To test the similarity between aquatic humic substances and HULIS, it may be fruitful to study ratios of absorbances, for example, $E_{250} / E_{365}\left(E_{2} / E_{3}\right)$. The $E_{2} / E_{3}$ ratio has been found to be inversely correlated with molecular weight and aromaticity in aquatic humic substances (Chin et al., 1994; Peuravuori et al., 2001). Duarte et al. (2005) reported that aerosol-derived HULIS had a higher $E_{2} / E_{3}$ ratio in summer samples than in autumn samples, a seasonal trend that correlated with lower aromaticity in summer samples as compared with autumn samples as confirmed by specific fluorescence intensity and ${ }^{13} \mathrm{C}$-NMR. UV-VIS absorbance may also be used to estimate HULIS molecular weight and aromaticity, based on correlations in the literature (Chin et al., 1994; Peuravuori and Pihlaja, 1997; Schafer et al., 2002).

\subsection{Fluorescence spectroscopy}

Fluorescence spectroscopy has also been applied to HULIS and WSOC extracts (Zappoli et al., 1999; Krivacsy et al., 2001a; Duarte et al., 2004; Duarte et al., 2005). Humic and fulvic acids exhibit fluorescence spectra that represent the summation of signals from a multicomponent mixture. Although fewer than $1 \%$ of the aromatic moieties in humic substances actually fluoresce, 3-D fluorescence spectroscopy is at least an order of magnitude more sensitive to humic substances than UV absorbance (Leenheer and Croue, 2003). Two distinct excitation (exc) ranges and emission (em) ranges have been found to characterize humic substances: $\lambda_{\text {exc }} 330-350$ and $\lambda_{\text {em }} 420-480$ (fulvic-like), and $\lambda_{\text {exc }} 250-260$ and $\lambda_{e m} 380-480 \mathrm{~nm}$ (humic-like) (Marhaba and Pu, 2000; Baker, 2001; Leenheer and Croue, 2003). Fluorescence of humic materials is strongly affected by UV absorbance (the stronger the UV absorbance, the higher the fluorescence emission), extent of complexation with metal ions or other organic molecules (quenches fluorescence), molecular weight, and molecular conformations. Humic fractions with lower average molecular weight (MW) have higher excitation and emission intensities, and a shift in peak position of the exc-em maximum towards lower wavelengths (Leenheer and Croue, 2003).

Excitation-emission fluorescence spectra for HULIS isolated from aerosol particles and fog water have peaks at shorter excitation and emission wavelengths than freshwater or terrestrial fulvic acids, suggesting a lower content of aromatic structures and condensed unsaturated bond systems, 

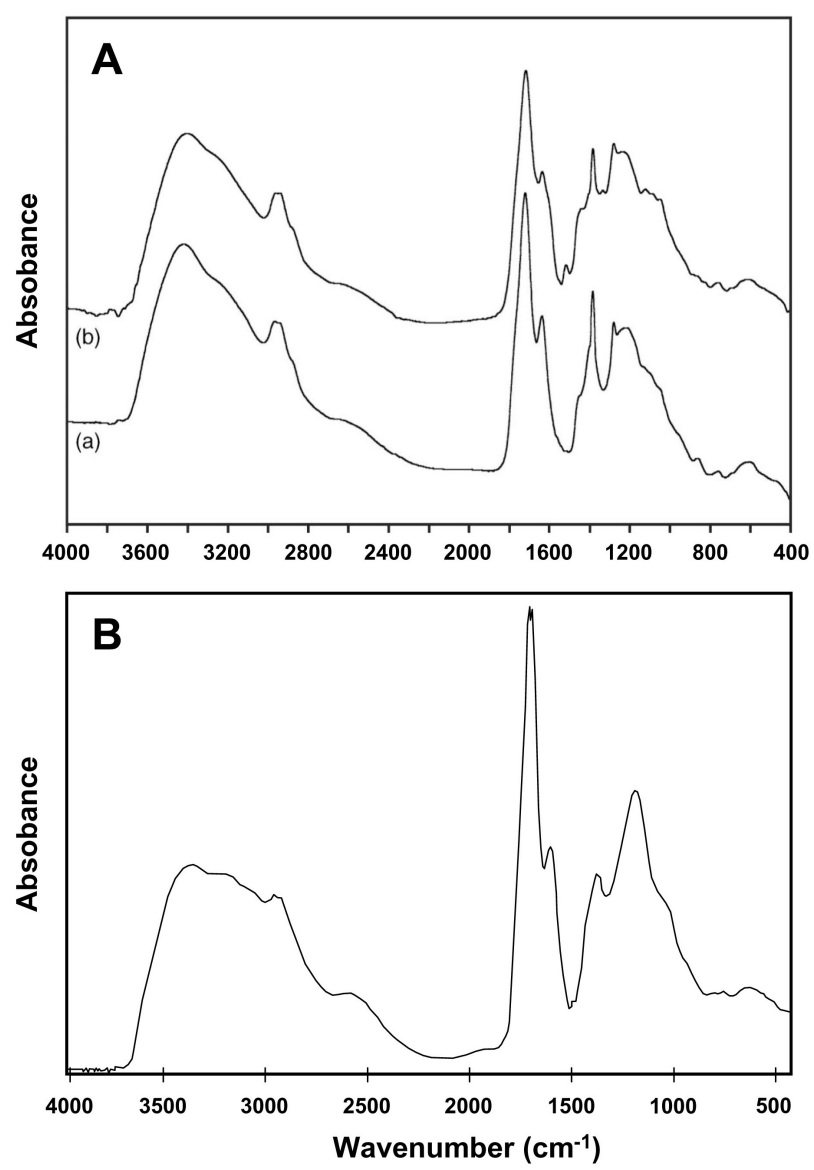

Fig. 2. (a) FTIR spectra of HULIS isolated from aqueous extracts of aerosol collected in summer (trace marked (a)) and autumn (trace marked (b)) from a rural area in Portugal. From Duarte et al. (2005; with permission). (b) FTIR spectrum for Suwannee River fulvic acid, from www.ihss.gatech.edu.

and a higher aliphatic moiety content in aerosol-derived HULIS (Krivacsy et al., 2000; Krivacsy et al., 2001a; Duarte et al., 2004; Duarte et al., 2005). The shift of fluorescence maxima towards shorter wavelengths in comparison to aquatic humic substances may also indicate the presence of solutes of lower MW (Peuravuori and Pihlaja, 1997; Duarte et al., 2004).

\subsection{IR spectroscopy}

IR spectra of humic substances are generally characterized by relatively few, very broad bands, and are thus apparently much simpler than spectra of pure substances. This apparent simplicity results from the fact that humic substances consist of complex multi-component mixtures of compounds, such that the resulting IR spectrum represents the net functional group content of all the components. Again, it should be born in mind that similar infrared spectra of such complex mixtures do not necessarily imply similar structures (Mac-
Carthy and Rice, 1985). With that caveat, it has been found that IR spectra of HULIS exhibit many features common to humic materials. For example, FTIR spectra of isolated HULIS from aerosol particles shown in Fig. 2a exhibit a broad band at $3400 \mathrm{~cm}^{-1}$ (assigned to OH-stretching of phenol, hydroxyl, and carboxyl groups), a shoulder in the region of $3000-2850 \mathrm{~cm}^{-1}$ (assigned to C-H stretching of methyl and methylene groups of aliphatic chains), a strong band near $1720 \mathrm{~cm}^{-1}$ (attributed to $\mathrm{C}=\mathrm{O}$ stretching), and a weak band in the $1600-1660 \mathrm{~cm}^{-1}$ region (attributed to $\mathrm{C}=\mathrm{C}$ stretching of aromatic rings and $\mathrm{C}=\mathrm{O}$ stretching of conjugated carbonyl groups), absorption at $1384 \mathrm{~cm}^{-1}$ (attributed to symmetrical $\mathrm{C}-\mathrm{H}$ bending vibrations from aliphatic $\mathrm{CH}_{3}$ ), a band in the $1220 \mathrm{~cm}^{-1}$ region (assigned to $\mathrm{C}-\mathrm{O}$ stretching and $\mathrm{O}$ $\mathrm{H}$ bending vibrations, mainly of $\mathrm{COOH}$ groups), and $\mathrm{C}-\mathrm{O}$ stretching of polysaccharides at $1061 \mathrm{~cm}^{-1}$ (Duarte et al., 2005). Due to varying spectral absorption coefficients and the relatively broad IR bands, these assignments suffer a certain degree of uncertainty (Havers et al., 1998). These FTIR spectra (Fig. 2a) were similar to others reported for WSOC from aerosol particles (Havers et al., 1998; Krivacsy et al., 2001a; Kiss et al., 2002). The similarity between the HULIS spectra from the study of Duarte et al. (2005) seen in Fig. 2a, and that for the Suwannee River Fulvic Acid (SRFA) standard from the IHSS (www.ihss.gatech.edu) shown for comparison in Fig. 2b, is notable.

\subsection{NMR spectroscopy}

\subsubsection{Proton-NMR $\left({ }^{1} \mathrm{H}-\mathrm{NMR}\right)$}

WSOC extracted from aerosol particles collected in the Po Valley in Italy, and fractionated on the basis of acidity was characterized by proton-NMR $\left({ }^{1} \mathrm{H}-\mathrm{NMR}\right)$ for functional group analysis (Decesari et al., 2000). The ${ }^{1} \mathrm{H}-\mathrm{NMR}$ spectrum of the first fraction, consisting of neutral/basic compounds, was interpreted to represent mainly polyhydroxylated or alkoxylated aliphatic compounds (polyols or polyethers). The spectrum of the second fraction was assigned to aliphatic carboxylic acids and hydroxyl-carboxylic acids. The ${ }^{1} \mathrm{H}-\mathrm{NMR}$ spectrum of the third polyacidic fraction (HULIS) had a more pronounced aromatic region than the other two fractions, and a much lower abundance of nonexchangeable organic protons, suggesting that the polyacids of the 3rd fraction (HULIS) had a much more unsaturated character than the acids of the 2nd fraction. A model structure consisting of an aromatic core bearing substituted aliphatic chains with $-\mathrm{COOH}, \mathrm{CH}_{2} \mathrm{OH},-\mathrm{COCH}_{3}$, or $-\mathrm{CH}_{3}$ terminal groups, was suggested to be consistent with the ${ }^{1} \mathrm{H}-\mathrm{NMR}$ features (Decesari et al., 2000). Such a structure is also consistent with electrospray ionization mass spectra of the acidic fraction of WSOC in fogwater (Cappiello et al., 2003), and with the structure earlier suggested by Mukai and Ambe (1986) on the basis of IR spectroscopy. 
${ }^{1} \mathrm{H}-\mathrm{NMR}$ spectroscopy has certain intrinsic drawbacks for the speciation of organic compounds. Information on the chemical environment of protons can be obtained from ${ }^{1} \mathrm{H}-$ NMR, but not on the carbon structure. Therefore, alternative interpretations of ${ }^{1} \mathrm{H}-\mathrm{NMR}$ spectra are possible. For example, a lack of (or low intensity) signal characteristic of aromatic protons indicates that the abundance of aromatic hydrogen is low. However, this may indicate either that the abundance of aromatic structures is low, or that most of the hydrogen atoms in the aromatic structures have been substituted by other moieties such as side chains or functional groups. These alternatives must be borne in mind when interpreting ${ }^{1} \mathrm{H}-\mathrm{NMR}$ spectra.

Another drawback in ${ }^{1} \mathrm{H}-\mathrm{NMR}$ is that acidic hydrogens (like those of $-\mathrm{OH}$ and $-\mathrm{COOH}$ groups) undergo chemical exchange with the $\mathrm{D}_{2} \mathrm{O}$ solvent and elude detection. A solution to this problem was recently presented by Tagliavini et al. (2005). They developed a derivatization procedure that converts carboxylic acids into their corresponding methyl esters, making it possible to observe them by ${ }^{1} \mathrm{H}-$ NMR, and thus determine the carboxylic group content in different aerosol samples. By fractionating aerosol WSOC into neutral, mono- and di-carboxylic acids (MDA), and polycarboxylic acids (PA) according to the method of Decesari et al. (2000), Tagliavini et al. (2005) used derivatization to determine the carboxylic group content of the different fractions. The polyacidic fraction, HULIS, had the highest $\mathrm{COOH}$ content (almost 1 carbon out of 7, or $13.25 \%$ ). The carboxylic group content of the MDA fraction was $11.76 \%$, and that of the neutral fraction, $2.54 \%$. The acidic content of the HULIS fraction was comparable to that reported for SRFA (Dinar et al., 2006) on the basis of acid titrations.

To convert $\mathrm{H}$ abundances into $\mathrm{C}$ abundances, it was necessary to guess specific $\mathrm{H} / \mathrm{C}$ ratios for the different functional groups (Fuzzi et al., 2001; Tagliavini et al., 2005). On this basis, the $\mathrm{H}$ content was converted into $\mathrm{C}$ content, bearing in mind that oxygenated carbons are detected only if the hydrogens bound to them are present (i.e., hydroxylated and alkoxylated aromatic carbons cannot be directly detected by ${ }^{1} \mathrm{H}$ NMR; (Tagliavini et al., 2005)). The C-converted aromatic abundance for the HULIS fraction was thus estimated to be about $19 \%$, which is a bit lower than the aromatic content determined by ${ }^{13} \mathrm{C}$-NMR for SRFA (22-24\%; www.ihss.gatech.edu) and much lower than that reported for Nordic Lake fulvic acid (31\%; www.ihss.gatech.edu). Aromatic contents of many humic acids are substantially greater than the 19\% reported for HULIS by Tagliavini et al. (2005), for example, two different batches of Suwannee River Humic Acid (SRHA) had $31 \%$ and $37 \%$ aromatic C, 3 soil samples between $45-58 \%$ aromatic $\mathrm{C}$, and a lake sample, $38 \%$ aromatic $\mathrm{C}$ (www.ihss.gatech.edu).

It may be anticipated that HULIS derived from different sources will possess significantly different spectral characters. For example, the ${ }^{1} \mathrm{H}-\mathrm{NMR}$ spectrum of a $\mathrm{D}_{2} \mathrm{O}$ extract of ozonated $n$-hexane soot, while fractionated almost exclu-
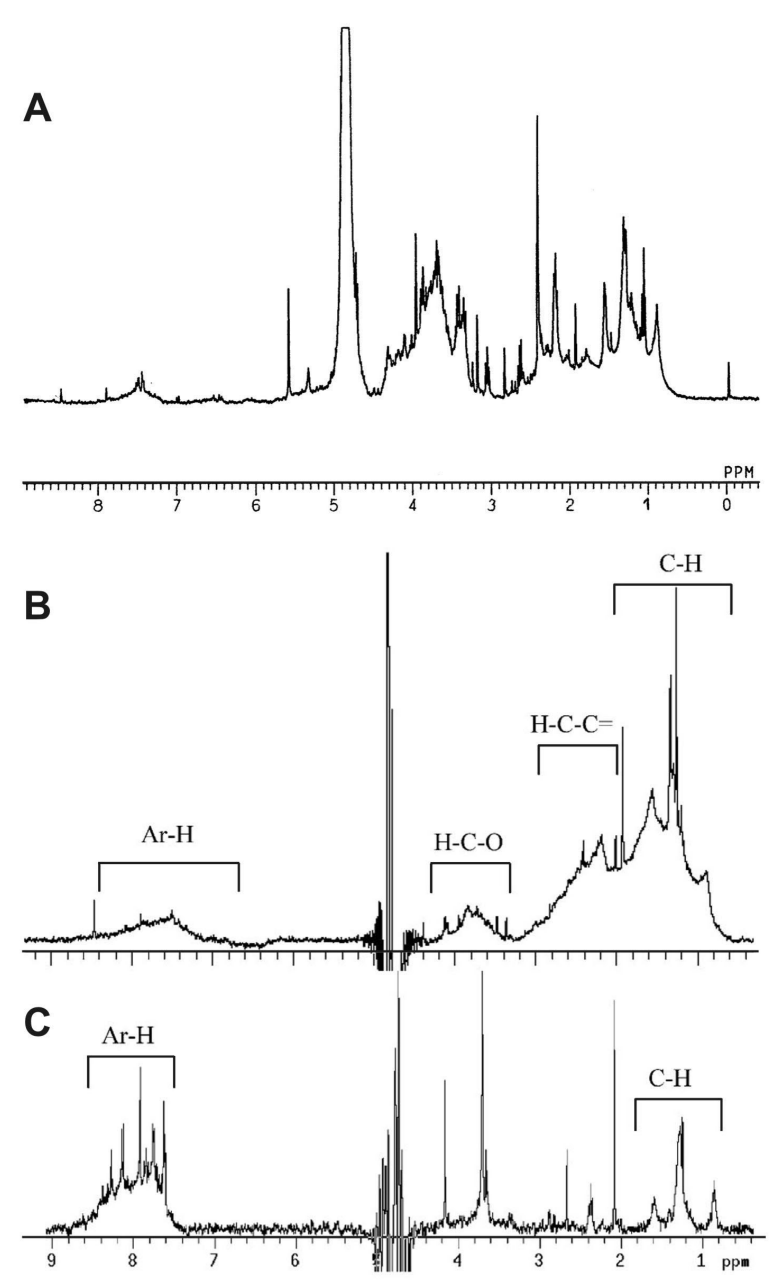

Fig. 3. (a) ${ }^{1} \mathrm{H}-\mathrm{NMR}$ spectrum for HULIS extracted from NIST urban dust. From Havers et al. (1998; with permission); (b) ${ }^{1} \mathrm{H}-\mathrm{NMR}$ spectrum for polyacidic fraction of an aerosol sample collected from the Po Valley. From Decasari et al. (2002; with permission); (c) ${ }^{1} \mathrm{H}-$ NMR spectrum for polyacidic fraction of $\mathrm{D}_{2} \mathrm{O}$ extract of ozonised soot. From Decasari et al. (2002; with permission).

sively into the polyacidic (HULIS) fraction (Decesari et al., 2000), differed significantly from that of the isolated polyacidic fraction from Po Valley ambient particles (Decesari et al., 2002). The spectrum for ozonated-soot HULIS was far richer in aromatic structures, with signals from rings substituted with electron-attracting groups such as carbonyl- and carboxyl-groups, and there was a marked scarcity of aliphatic structures (Decesari et al., 2002) (Fig. 3c).

In an earlier ${ }^{1} \mathrm{H}-\mathrm{NMR}$ study of HULIS extracted from NIST 1648 dust by Havers et al. (1998), it was reported that $\mathrm{H}$ atoms were present principally in polysaccharide (about $40 \%$ ) and aliphatic substructures (about 50\%), and only to a small extent in aromatic structures. Yet, it must be recalled that a low intensity of aromatic protons may either indicate that the abundance of aromatic structures is low, or that many 
of the hydrogen atoms in the aromatic structures have been substituted by other moieties. The ${ }^{1} \mathrm{H}-\mathrm{NMR}$ spectrum in Havers et al. (1998) was most similar to that presented by Decesari et al. (2000) for the mono- and di-carboxylic acid fraction (Fig. 3b), and is rather dissimilar to the spectrum of the polyacidic (HULIS) fraction (Fig. 3a). Considering that the DEAE-cellulose resin used for concentration by Havers et al. (1998) does not segregate low molecular weight organic acids, a considerable fraction of the HULIS studied in that work may consist of lower molecular weight organic acids. Indeed, Havers et al. (1998) found that virtually all the extracted material passed through an ultrafiltration membrane with a 1000 Da nominal cutoff.

\subsection{2 ${ }^{13} \mathrm{C}-\mathrm{NMR}$}

One of the only studies to specifically concentrate on the base-soluble, acid-insoluble humic acid fraction of organic matter in aerosol particles was by Subbalakshmi et al. (2000). In that study, ${ }^{13} \mathrm{C}-\mathrm{NMR}$ characterization of the base-extracted and dialysized humic acid (dialysis cutoff 12$14 \mathrm{kDa}$ ) obtained from fresh urban particulate matter showed a spectrum consisting of about $45 \%$ aliphatic $\mathrm{C}$ and a large aromatic component (41\%), similar in abundances to soil and aquatic-derived humic acids.

Duarte et al. (2005) reported ${ }^{13} \mathrm{C}-\mathrm{NMR}$ spectra for HULIS extracted from the WSOC fraction of summer and autumn aerosol particles from a rural part of Portugal. The spectra showed a broad range of un-substituted saturated aliphatic components (resonance in the 10 to $50 \mathrm{ppm}$ range), aliphatic carbons singly bound to one oxygen or nitrogen atom (60$95 \mathrm{ppm}$ range), aliphatic carbons singly bound to two oxygen atoms (95-110 ppm range), and ester and carboxyl carbons (160-190 ppm range) (Duarte et al., 2005). The autumn sample was relatively richer in aromatic carbons (110 $160 \mathrm{ppm}$ range) than the summer sample (Fig. 4a), which the authors concluded reflected a lignin breakdown component due to wood burning. Unfortunately, they did not provide estimates for percent of aromatic carbons in the WSOC-derived HULIS samples, although in both cases (summer and autumn), it was evident from the NMR spectra that the relative abundance of aromatic $\mathrm{C}$ in these WSOC-derived HULIS samples was much lower than that reported by Subbalakshmi et al. (2000) for aerosol-derived humic acid (base-extracted), and lower than that reported by the IHSS for SRFA (Fig. 4b) and Nordic Lake FA.

A substantial difference in ${ }^{13} \mathrm{C}$-NMR spectra for HULIS extracted from the WSOC fraction of urban aerosol and biomass aerosol was reported by Sannigrahi et al. (2005). Biomass burning HULIS had a significantly higher aromatic carbon percentage than did urban aerosol HULIS. Both HULIS samples were found to have a substantial aliphatic component, and to be quite different in relative carbon distribution from a humic acid standard.

\section{Non-spectroscopic characterization}

A variety of other characterization methods have been employed in the search for HULIS structure. These studies are reviewed below.

\subsection{Pyrolysis Gas Chromatography/Mass Spectroscopy (GC/MS)}

Gelencser et al. (2000b) employed derivitization pyrolysis GC/MS to study the chemical structure of the bulk polymeric matter in continental fine aerosol particles. Filters containing fine aerosol particles were treated by tetramethylammoniumhydroxide (TMAH) to achieve high temperature methylation of carboxylic and hydroxyl groups during pyrolysis at $500^{\circ} \mathrm{C}$. In summer samples, the identified compounds largely consisted of methyl esters of $n$-alkanoic acids (C10-C18), $\alpha, \omega$-alkandioic acids (C4-C9), benzene mono-, di-, and tricarboxylic acids, methoxy-acetic and methoxy-benzoic acid, and a few other $\mathrm{N}$-containing compounds (glycine derivatives). The TMAH-pyrolysis products for winter samples were very different, being comprised almost exclusively of fatty acid methyl esters. The authors interpreted their results in terms of a polymeric material consisting of benzenecarboxylic acids as building blocks with attached aliphatic moieties, although indeed, there is no evidence for such a structure in the winter aerosol. These results of Gelencser et al. (2000b) cannot be strictly attributed to a polymeric portion of the organic aerosol, as no efforts were made to separate a high molecular weight fraction from a low molecular weight fraction before pyrolysis. This study can be contrasted with that of Subbalakshmi et al. (2000), who compared pyrograms and TMAH-derivatized pyrograms of urban aerosol and base-extracted, acid-precipitated humic acid extracted from the urban aerosol. The pyrolitic components of the extracted humic acid revealed oxygen, nitrogen and sulfur-bearing compounds, substituted benzenes, substituted naphthalenes, and aliphatic, aromatic and cyclic hydrocarbons, several of which could be identified as originating from four biomolecule classes: lignin, protein, carbohydrates, and lipids. The derivatized pyrogram (for polar group analysis) of the whole aerosol sample revealed a number of aliphatic acid products (mainly methyl esters of $n$-alkanoic acids in the C14-C18 range), aromatic acids (like Gelencser et al. (2000b)), and phenolic compounds.

\subsection{Capillary electrophoresis}

Capillary electrophoresis was applied to interstitial aerosol and fog water samples collected in the Po Valley and a standard humic acid (Nordic River humic acid (NRHA) from the IHSS) (Krivacsy et al., 2000). Electropherograms with typically broad humps representing a multitude of compounds of differing charge to size ratios were obtained for the NRHA standard, with better resolution in the borate buffer as 

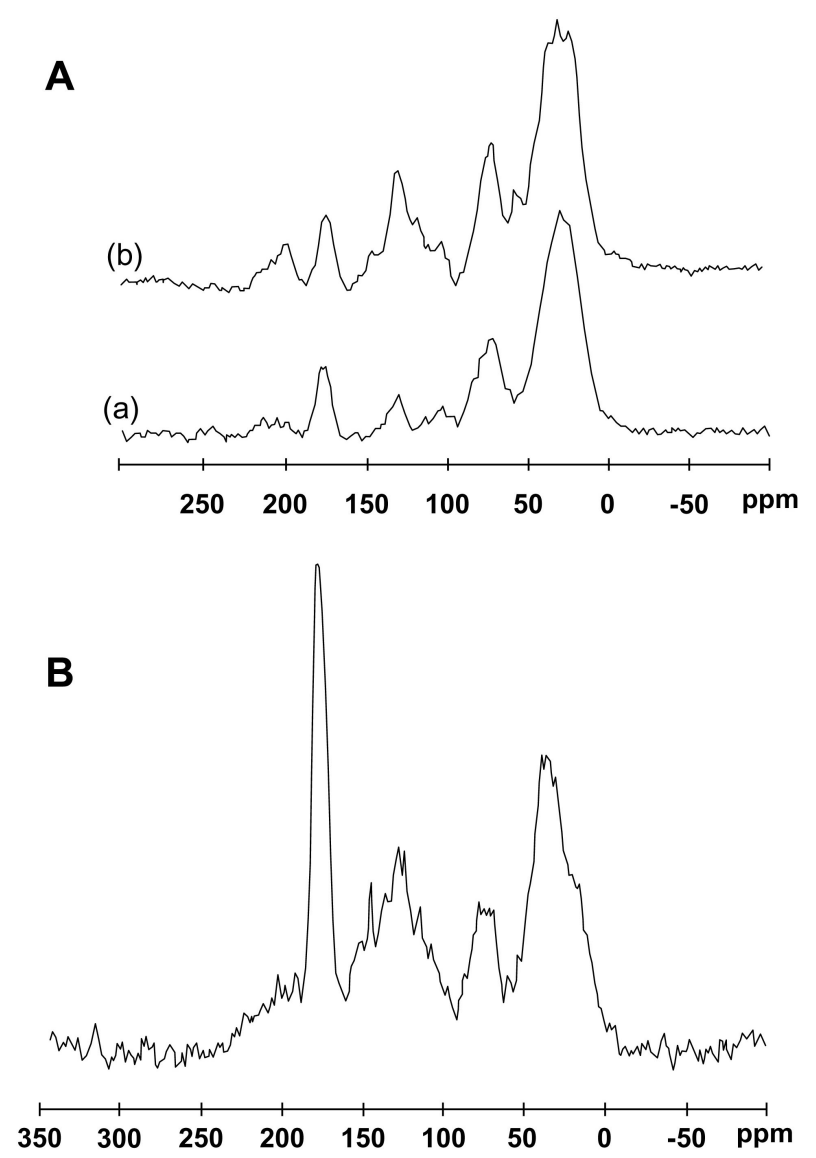

Fig. 4. (a) ${ }^{13} \mathrm{C}-\mathrm{NMR}$ spectra for HULIS isolated from aqueous extracts of aerosol collected in summer (trace marked (a)) and autumn (trace marked (b)) from a rural area in Portugal. From Duarte et al. (2005; with permission). (b) ${ }^{13} \mathrm{C}$-NMR spectrum for Suwannee River fulvic acid, from www.ihss.gatech.edu.

compared with the phosphate buffer (Fig. 5a) due to complex formation between borate and humic acid 1,2- and 1,3-diol groups. In contrast, the broad hump of the electropherograms of interstitial aerosol occurred over a shorter migration time range (Fig. 5b), indicating overall lower mobility of ionic compounds, with many small peaks superimposed over the hump. There was little difference in electrophoretic behavior in the two buffers (Fig. 5b), demonstrating a negligible amount of 1,2- and 1,3-diol groups in the aerosol sample. Electrophoretic mobility of the aerosol sample increased continuously with increasing $\mathrm{pH}$ of the electrolyte, with a sharp increase between 4.28 and 5.90, and a slower increase in the $\mathrm{pH}$ range of 5.90-9.10. At $\mathrm{pH} 4.28$, the interstitial aerosol electrophoretic hump disappeared entirely, suggesting that most of the acidic functional groups were protonated. Yet, the HA sample retained substantial electrophoretic mobility at pH 4.28. In this study, Krivacsy et al. (2000) used the term HULIS to refer to the entire interstitial aerosol sample, which is very likely not the case. The hump may represent a
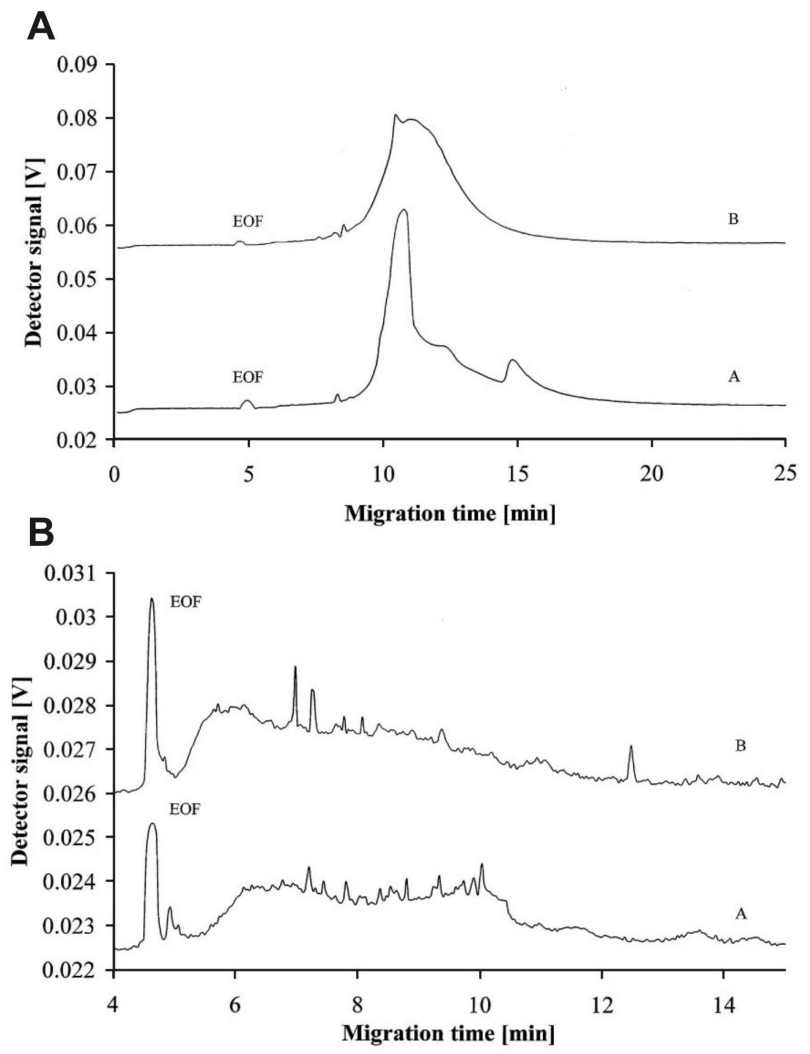

Fig. 5. (a) Electropherograms of Nordic River humic acid in $6 \mathrm{mM}$ $\mathrm{Na}_{2} \mathrm{~B}_{4} \mathrm{O}_{7} \cdot 10 \mathrm{H}_{2} \mathrm{O}-3 \mathrm{mM} \mathrm{KH}{ }_{2} \mathrm{PO}_{4}, \mathrm{pH}=9.00$ (trace marked A) and in $5 \mathrm{mM} \mathrm{NaHPO}, \mathrm{pH}=9.10$ (trace marked $\mathrm{B}$ ); and (b) Electropherograms of water extract of an interstitial aerosol sample in $6 \mathrm{mM} \mathrm{Na}_{2} \mathrm{~B}_{4} \mathrm{O}_{7} \cdot 10 \mathrm{H}_{2} \mathrm{O}-3 \mathrm{mM} \mathrm{KH} \mathrm{KH}_{4}, \mathrm{pH}=9.00$ (trace marked A) and in $5 \mathrm{mM} \mathrm{NaHPO}, \mathrm{pH}=9.10$ (trace marked B). From Krivacsy et al. (2000; with permission).

large number of LMW compounds, and certainly, there were substantial differences in electrophoretic activity and chemical character between the standard and the tested samples.

Electrophoretic behavior of isolated WSOC from alpine aerosol particles was also studied by Krivacsy et al. (2001a). They found no indication of phenolic $\mathrm{OHs}$, and reported that at $\mathrm{pH}$ of about 4 , the majority of the compounds were neutralized, confirming earlier results (Krivacsy et al., 2000), and demonstrating the weakly acidic nature of the isolated WSOC, apparently weaker than the humic acid studied for comparison.

\subsection{Elemental analysis}

Average elemental composition $(\mathrm{m} / \mathrm{m} \%)$ of HULIS from the WSOC fraction of rural fine aerosol particles collected between Jan-Sept 2000 in Hungary was reported to be $52 \%$ $\mathrm{C}, 6.2 \% \mathrm{H}, 2.5 \% \mathrm{~N}$, and $39 \% \mathrm{O}$, giving an average organic matter mass to organic carbon ratio of 1.93 , an average $\mathrm{O} / \mathrm{C}$ molar ratio of 0.58 , and an average $\mathrm{H} / \mathrm{C}$ molar 


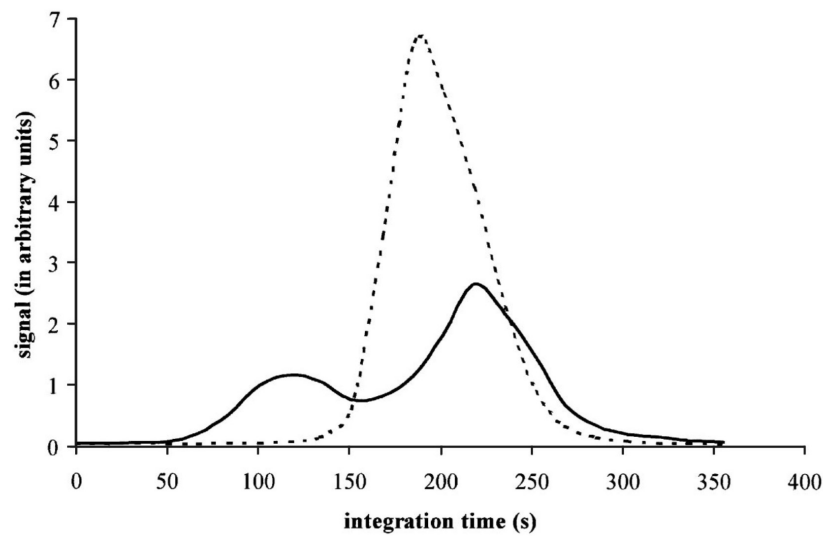

Fig. 6. Thermal profile of lignite-derived humic acid (dotted line) and of fine mode aerosol (solid line) from rural Hungary. From Gelescner et al. (2000a; with permission).

ratio of 1.42 (Kiss et al., 2002). The elemental composition was quite invariant throughout the whole sampling period. These results were very similar to those obtained earlier by Krivacsy et at. (2001a) for HULIS from alpine rural aerosol particles $(52.3 \% \mathrm{C}, 6.7 \% \mathrm{H}, 2.5 \% \mathrm{~N}$, and $38.5 \%$ $\mathrm{O}$ ), giving an $\mathrm{O} / \mathrm{C}$ molar ratio of 0.55 and $\mathrm{H} / \mathrm{C}$ molar ratio of 1.58. While reported $\mathrm{O} / \mathrm{C}$ molar ratios are similar to those for standard fulvic acids, the $\mathrm{H} / \mathrm{C}$ molar ratios are substantially higher. Compare for example, molar ratios for Suwannee River fulvic acid (O/C 0.60; H/C 0.99) and Nordic Lake FA (O/C $0.65 ; \mathrm{H} / \mathrm{C} 0.91$; calculated from data provided by IHSS; www.ihss.gatech.edu). Thus, the elemental analysis of HULIS indicates a predominance of oxygenated functional groups, and the presence of saturated systems in excess of that for aquatic fulvic acids. This corresponds to certain spectral results (UV-VIS, fluorescence, ${ }^{13} \mathrm{C}-\mathrm{NMR},{ }^{1} \mathrm{H}-$ NMR) that indicate a relatively lower aromatic content for WSOC-derived HULIS as compared with fulvic and humic acids (Havers et al., 1998; Krivacsy et al., 2001a; Duarte et al., 2004; Duarte et al., 2005; Tagliavini et al., 2005). Based on elemental and spectroscopic results, Kiss et al. (2002) concluded that HULIS isolated from water soluble organic carbon fraction consists of polyfunctional compounds bearing polyconjugated structural elements, and carrying polar groups such as carboxyl, hydroxyl and carbonyl. This fits well with the model structure consisting of an aromatic core bearing substituted aliphatic chains with $-\mathrm{COOH}, \mathrm{CH}_{2} \mathrm{OH}$, $-\mathrm{COCH}_{3}$, or $-\mathrm{CH}_{3}$ terminals groups suggested by others (Mukai and Ambe, 1986; Decesari et al., 2000; Cappiello et al., 2003).

\subsection{Thermal profiling}

A few attempts have been made to apply thermal profiling techniques to the study of atmospheric HULIS, with ambiguous results. Thermograms of fine continental aerosol revealed two distinct peaks (Fig. 6), the first of which was attributed to more volatile or easily oxidizable compounds, while the second was attributed to "air polymers" (Gelencser et al., 2000a). Yet, a comparative thermogram of lignitederived humic acid (Aldrich Company) demonstrated a single peak with a maximal peak height distinctly offset to a lower time (temperature) than that of the "air polymer" peak of the aerosol sample (Fig. 6). Following Francioso et al. (2005), it can be expected that a humic material which has undergone a relatively large extent of diagenetic changes and humification such as the lignite-derived humic acid sample from Aldrich studied by Gelencser et al. (2000a), should be more thermally refractive than the smaller, less condensed and less altered HULIS, and not the reverse.

A similarly unexplainable result is seen in the study by $\mathrm{Yu}$ et al. (2004), whereby the thermogram component that was suggested to represent high molecular weight organic species (i.e., HULIS), demonstrates more refractive behavior than a humic acid standard. Inconsistent with the interpretation of high MW is the thermogram for a levoglucosan standard, where a late peak is seen to evolve at the same time as the so-called "high MW" peak.

\subsection{Size exclusion chromatography (SEC)}

Size exclusion chromatography has been employed in different attempts to characterize WSOC aerosol extracts (Mukai and Ambe, 1986; Zappoli et al., 1999; Krivacsy et al., 2000; Andracchio et al., 2002; Samburova et al., 2005a), but it has proved difficult to extract consistent and significant molecular size information with this technique. SEC characterization of complex multicomponent mixtures of polyfunctional polyelectrolytes such as humic substances is well-known to be difficult due to the preponderance of separation mechanisms other than size exclusion (e.g., electrostatic and molecular interactions with the stationary phase). At this time, after years of application of SEC to humic materials, optimal elution and detection systems, as well as molecular size interpretations of chromatograms, are still quite controversial (Chin et al., 1994; Peuravuori and Pihlaja, 1997; Perminova et al., 1998; DeNobili and Chen 1999; Perminova 1999; Piccolo et al. 1999; Kudryavtsev et al. 2000; Perminova et al., 2003; Piccolo et al., 2003; Peuravuori and Pihlaja, 2004) etc. A recent study by Samburova et al. (2005a) of WSOC extracted from urban aerosol from Zurich exemplifies this difficulty, displaying differences in estimated molecular size by nearly an order of magnitude as a function of the polymer standard applied.

\subsection{Ultrafiltration}

One of the more perplexing issues concerning HULIS characterization is related to its ultrafiltration behavior, whereby virtually all organic carbon from WSOC aerosol extracts passes through ultrafiltration membranes of 500 or $1000 \mathrm{Da}$ 


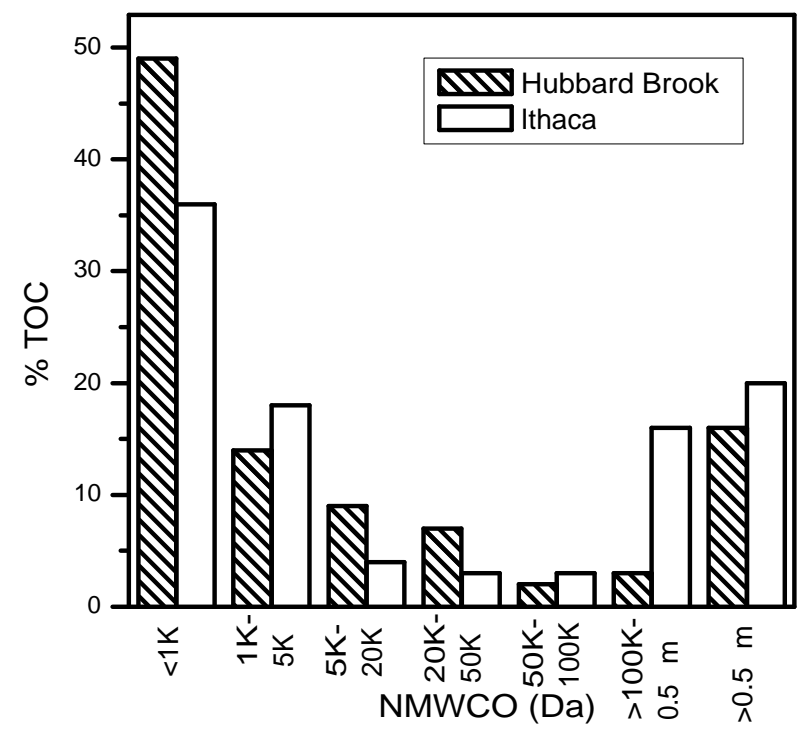

Fig. 7. Size distribution of total organic carbon in precipitation from two sites in rural NY. After Likens and Galloway (1983; with permission).

(Havers et al., 1998; Krivacsy et al., 2001a; Kiss et al., 2003). Such behavior stands in sharp contrast to myriad reports for ultrafiltration of fulvic and humic acids, which are routinely separated into ultrafiltration fractions by nominal cutoffs even as high as 100000 Da (Aiken, 1984; Marley et al., 1992; Ikeda et al., 2000; Subbalakshmi et al., 2000; Clark et al., 2002; Francioso et al., 2002; Alberts and Takacs, 2004; Assemi et al., 2004; Peuravuori et al., 2005; Schwede-Thomas et al., 2005). Such fractionation, though not considered to represent the true molecular weight of the fractions due to complex ion repulsion and filter clogging phenomenon, nevertheless are frequently found to segregate humic and fulvic acids according to chemical structure. Even more confounding is that one of the earliest studies to report macromolecular organic carbon in precipitation, Likens and Galloway (1983), partitioned dissolved organic carbon (DOC) in rainwater collected from a rural area into different molecular weight ranges by ultrafiltration at nominal molecular weight cut-offs (NMWCO) of 1000, 5000, 20000 , 50000, and $100000 \mathrm{Da}$. About $50 \%$ of the DOC passed the 1000 Da membrane, while the rest was segregated by NMWCO up to $100000 \mathrm{Da}$ (Fig. 7). The low molecular weight fraction $(<1000 \mathrm{NMWCO})$, representing about 37$47 \%$ of the rainwater total organic carbon (TOC), yielded significant concentrations of carboxylic acids, aldehydes, carbohydrates, and tannin/lignin. These results beg the question of whether the WSOC fraction frequently studied as HULIS does indeed contain a substantial macromolecular portion, or whether HULIS actually reflects a complex mixture of inseparable low molecular weight compounds. This question leads to studies of molecular weight determinations by MS detection.
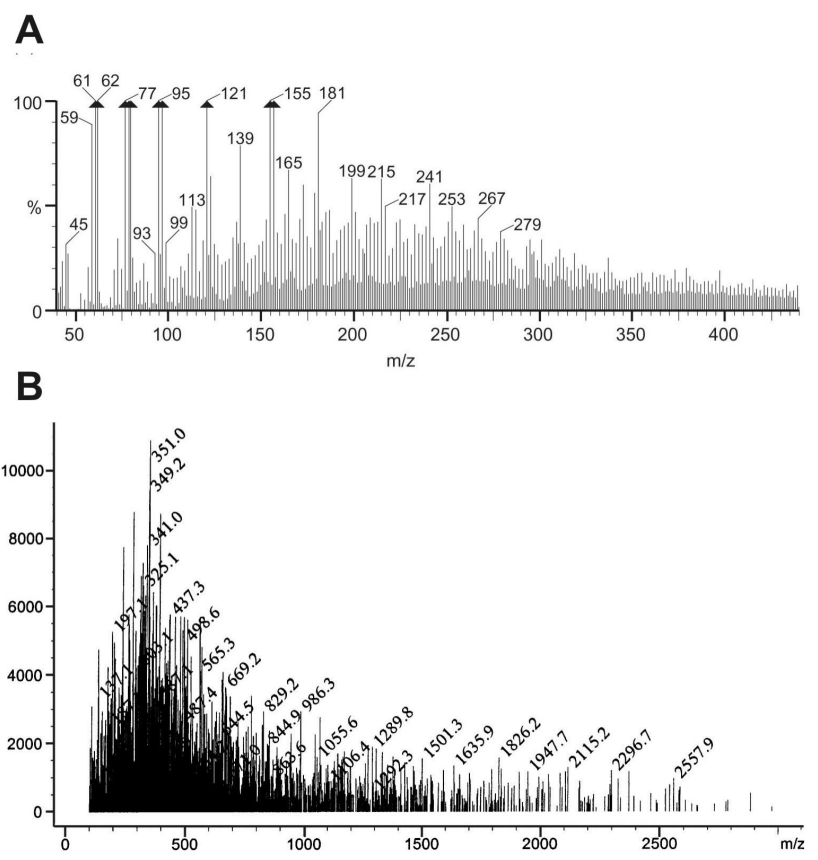

Fig. 8. (a) ESI-MS negative ion spectrum of HULIS extracted and isolated from aerosol collected in Hungary. From Kiss et al. (2003; with permission); (b) ESI-MS spectra in negative ion mode obtained for Suwannee River Fulvic Acid. From Rostad and Leenheer (2004; with permission).

\section{Molecular weight determination by MS}

To now, there have been few attempts to characterize isolated HULIS by molecular weight. One of the only studies to do so was by Kiss et al. (2003), who tried to estimate average molecular weight of HULIS that was isolated from the WSOC extract of rural aerosol samples by the technique of Varga et al. (2001). The isolate had considerable absorbance in the $200-500 \mathrm{~nm}$ range, indicating the presence of polyconjugated organic compounds. Liquid chromatography and concomitant photodiode array detection and electrospray ionization (ESI) tandem quadrupole mass spectrometer in negative ionization mode was applied, with mass spectra recorded in the range of $m / z$ from 40 to $520 \mathrm{Da}$. The electrospray mass spectra demonstrated a mixture of negative ions of varying $m / z$ ratio, with a unimodal distribution and a tail towards higher $m / z$ (Fig. 8a). Weight average molecular weight $\left(\mathrm{MW}_{\mathrm{W}}\right)$, determined by assuming all the ions are singly charged, was computed to range between about 200 to 300 Da. For comparison, a negative ion mode ESI-MS spectra for Suwannee River fulvic acid (SRFA) from Rostad and Leenheer (2004) is shown in Fig. 8b. The fulvic acid spectra displays a unimodel distribution of negative ions with a long tail towards $\mathrm{m} / \mathrm{z}$ ratios greater than $2500 \mathrm{Da}$ and an average MW $\mathrm{W}_{\mathrm{W}}$ of $456 \mathrm{Da}$ (Fig. 8b) (Rostad and Leenheer, 2004). Other studies have shown uni- or multi-modal negative ion 
distributions for fulvic acids with $\mathrm{m} / \mathrm{z}$ ratios extending well beyond $1000 \mathrm{Da}$ (Brown and Rice, 2000a; Persson et al., 2000; Pfeifer et al., 2001; Stenson et al., 2002; Reemtsma and These, 2003).

Possible sources of error in such molecular weight determinations by ESI-MS in negative ion mode are manifold, including fragmentation in the ESI source, formation of multiply-charged ions, and differing ionization and detection efficiencies for diverse components of the complex mixture of compounds making up HULIS. These sources of error can be difficult to test or quantify. Recent studies using high resolution mass spectrometry have shown that virtually all ions in fulvic and humic acid spectra are singly-charged (Stenson et al., 2002; Reemtsma and These, 2003; Rostad and Leenheer, 2004), alleviating concerns raised by earlier reports that formation of multiply-charged ions may be potentially significant (Brown and Rice, 2000a; Persson et al., 2000; Leenheer et al., 2001; Pfeifer et al., 2001). Other parameters found to considerably affect molecular mass determinations by ESI-MS of fulvic (and humic) acids include solution concentration, $\mathrm{pH}$, ionic strength, and complexity (Brown and Rice, 2000a; Persson et al., 2000; Piccolo and Spiteller, 2003; Rostad and Leenheer, 2004; These et al., 2004). Likewise, $m / z$ ion distribution range and intensity may vary greatly as a function of spray solvent composition, positive versus negative ion detection mode, and cone voltage (Brown and Rice, 2000a; Persson et al., 2000; These and Reemtsma, 2003; Rostad and Leenheer, 2004). Considering that ionization and detection of higher MW components is less efficient, that solution complexity reduces the overall $\mathrm{m} / \mathrm{z}$ distribution, and the limited stability of the higher molecular weight humic and fulvic acid molecules in the electrospray process, there seems to be a growing consensus that ESI-MS analytical ability for fulvic and humic acids may be limited to about 1000 Da for molecular ions (Kujawinski et al., 2002; Stenson et al., 2002; Piccolo and Spiteller, 2003; Reemtsma and These, 2003; These and Reemtsma, 2003; Rostad and Leenheer, 2004).

Because of uncertainties with ESI-MS molecular weight estimates, particularly concerns of possible negative bias due to formation of multiply-charged ions, and lower ionization and detection efficiency for high MW molecules, Kiss et al. (2003) also estimated number average molecular weight $\left(\mathrm{MW}_{\mathrm{N}}\right)$ by isothermal vapor pressure osmometry. Number average estimates ranged from about 215 to $345 \mathrm{Da}$, whereas molecular weight mass estimates $\left(\mathrm{MW}_{\mathrm{M}}\right)$ from ESI-MS were somewhat lower, in the range of about 200 to $300 \mathrm{Da}$. Ideally, $\mathrm{MW}_{\mathrm{M}}$ should be greater than or equal to $\mathrm{MW}_{\mathrm{N}}$. The ratio between the two, $\mathrm{MW}_{\mathrm{M}} / \mathrm{MW}_{\mathrm{N}}$, is a measure of polydispersivity, with a higher ratio indicating a greater polydispersivity. $\mathrm{MW}_{\mathrm{N}}$ represents the total weight of the molecules present divided by the total number of molecules. $\mathrm{MW}_{\mathrm{W}}$ is a weighted average considering the mass of the molecules, so that heavier molecules have relatively more importance than lighter molecules. Possible explanations for higher $\mathrm{MW}_{\mathrm{N}}$ than $\mathrm{MW}_{\mathrm{M}}$ include HULIS aggregation in the osmometry experimental solution, or negative bias in the MS spectral calculations (Kiss et al., 2003).

Other studies have employed ESI-MS for characterizing $\mathrm{m} / \mathrm{z}$ ion distributions of WSOC from aerosol particles (Krivacsy et al., 2001a; Samburova et al., 2005a; Samburova et al., 2005b), fog water (Krivacsy et al., 2000; Kiss et al., 2001; Cappiello et al., 2003), and cloud water (Feng and Moller, 2004), without isolating the HULIS fraction from other water soluble compounds. For un-fractionated WSOC from rural aerosol particles, an $\mathrm{m} / \mathrm{z}$ ion distribution range from 53 to 303 in negative ion mode was obtained (Krivacsy et al., 2001a). The authors specifically acknowledged that the presence of inorganic ions (which suppress the ionization of organic compounds), formation of water adducts (ions combined with different number of water molecules), and lack of information on the charge state of the ions, may all have resulted in unrepresentative MW determination. As in the later study of Kiss et al. (2003), Krivacsy et al. (2001a) found that all WSOC passed through a 500 Da ultrafiltration membrane. For water extracts of urban airborne particulate matter, laser desorption ionization mass spectra (LDI-MS) showed a unimodal distribution of peaks with a range between $\mathrm{m} / \mathrm{z} 100$ 600 (Samburova et al., 2005a; Samburova et al., 2005b).

Bulk fog water samples evaluated by ESI tandem quadrupole MS in negative ionization mode demonstrated a vast number of peaks giving an unresolved hump of ions from $m / z=100$ to 600 , with the most intense peaks being detected around $m / z=200-250$ (Kiss et al., 2001). The Nordic River fulvic acid (NRFA) standard analyzed for comparison likewise demonstrated an unresolved hump of ions, but with a broader range of masses, ranging from $\mathrm{m} / \mathrm{z}$ of 140 up to $1000 \mathrm{Da}$ (or higher), with the most intense peaks at around $m / z=300$. Krivacsy et al. (2000), also studying unfractionated fog water and a humic acid standard (Nordic River HA) in negative ion mode by ESI-MS, reported an ion mass range for fog water from 50 to $500 \mathrm{~m} / \mathrm{z}$, with the most intense peaks in the $m / z=150-200$ range. The most intense peaks of the HA standard were in the $200-250 \mathrm{~m} / \mathrm{z}$ range, with an $m / z$ ion range greater than 600 . Krivacsy et al. (2000) were careful not to attribute these $\mathrm{m} / \mathrm{z}$ ratios to actual average molecular weight distributions. Cappiello et al. (2003) also characterized bulk water soluble compounds from fog water in negative ion mode, using ESI- ion trap MS/MS (ESI-MS/MS). While they did not attempt to determine MW, it is of interest to note that both fog water samples and Suwannee River fulvic acid (SRFA) displayed continuous ion profiles of $m / z$ ratios up to $1000 \mathrm{Da}$ (mass distributions measured from 100 to $1000 \mathrm{Da}$ ). The WSOC obtained from fog samples had slightly greater abundances of ions in the lower part of the mass spectrum, which may reflect the fact that a separate HULIS fraction was not isolated from the LMW organics before ESI-MS/MS analysis (Cappiello et al., 2003). Feng and Moller (2004) reported ESI-MS results for bulk cloud water samples, observing an $\mathrm{m} / \mathrm{z}$ range for nega- 
tive ions from about 100 to $500 \mathrm{Da}$, with the most intensive peaks in the 250-300 Da range.

With the exception of Kiss et al. (2003), these studies have characterized whole samples or the entire water soluble fraction. Clearly, if HULIS is not separated from LMW organic compounds, average MW determinations will be skewed towards lower average weights. Additionally, as relatively higher molecular weight compounds have been found to undergo less effective ionization and detection (Reemtsma and These, 2003), it is obvious that a MW determination for unfractionated WSOC will necessarily underestimate HULIS average mass determination. The extreme complexity of the unfractionated samples will also skew the $m / z$ range to lower values, due to spray, ionization, and detection inefficiencies (Piccolo and Spiteller, 2003; Reemtsma and These, 2003; These and Reemtsma, 2003). For these and many other reasons, molecular weight determinations reported for HULIS should be viewed with caution. It should also be reiterated that mass spectrometer studies of fulvic and humic acids have generally shown demonstrably larger ranges of $m / z$ ratio and greater average molecular weight estimates than those reported for atmospheric samples (Brown and Rice, 2000b; Brown and Rice, 2000a; Persson et al., 2000; Leenheer et al., 2001; Pfeifer et al., 2001; Plancque et al., 2001; Stenson et al., 2002; Piccolo and Spiteller, 2003; Reemtsma and These, 2003; Stenson et al., 2003; These and Reemtsma, 2003; Rostad and Leenheer, 2004; These et al., 2004).

\section{Hygroscopic properties, surface activity, and colloidal properties}

\subsection{Hygroscopic growth}

To date, a limited number of studies have examined the hygroscopic growth and deliquescence behavior of atmospheric HULIS or model HULIS material. Gysel et al. (2004) examined hygroscopic behavior of water soluble matter (WSM) and isolated organic matter (HULIS using the method of Varga et al. (2001)) derived from ambient continental-rural fine aerosol samples, as well as aquatic reference fulvic and humic acids, by hygroscopic tandem differential mobility analyzer (H-TDMA) at sub-saturation (5-95\% relative humidity; RH). The ideal solution model was found to describe HULIS and reference humic materials' growth curves well, assuming no dissociation. Growth factors at $90 \% \mathrm{RH}$ for HULIS and humic materials ranged from 1.06 to 1.18 . Similar growth factors for standard humic and fulvic acids obtained from the IHSS were also observed by Brooks et al. (2004) for particles of 50, 100 and $200 \mathrm{~nm}$ diameter, and for Suwannee River Fulvic Acid (SRFA; Svenningsson et al., 2005).

Hygroscopicity of bulk model humic materials (SRFA and Nordic Aquatic Fulvic Acid (NAFA)) was also studied by electrodynamic balance (Chan and Chan, 2003). They reported that both humic materials absorbed and desorbed water reversibly without crystallization, and retained water at $\mathrm{RH}<10 \%$. This may be ascribed to the fact that humic substances are anionic in aqueous solution, and will not dehydrate unless the charges are sufficiently neutralized (Gorbunov et al., 1998; Yates and von Wandruszka, 1999). Growth factors at $\mathrm{RH}=90 \%$ were 1.13 and 1.21 for SFRA and NAFA, respectively, similar to growth factors measured by H-TDMA for similar reference materials.

Gysel et al. (2004) suggested the occurrence of deliquescence for HULIS and humic materials based on a shrinkage in mobility diameter at an intermediate RH, which they attributed to an initial dynamic shape factor $>1$ that led to a decrease in mobility diameter upon dissolution of the particles. Yet, other studies failed to identify deliquescence for humic and fulvic acids (Chan and Chan, 2003; Brooks et al., 2004; Svenningsson et al., 2005). No apparent relationship between deliquescence RH (DRH) of the different samples and their $90 \% \mathrm{RH}$ growth factor could be discerned in the study of Gysel et al. (2004).

Chan and Chan (2003) and Brooks et al. (2004) studied hygroscopic growth of mixtures of humic substances with inorganic salts such as ammonium sulfate (AS) and $\mathrm{NaCl}$. Svenningsson et al. (2005) also studied hygroscopic growth and CCN activity of mixtures of small organic acids, fulvic acid, and inorganic salts. Model HULIS materials are less hygroscopic than either $\mathrm{NaCL}$ or AS, such that mixtures absorb less water than equal masses of the pure inorganic salts. Mixtures were found to deliquesce at RHs similar to DRHs of the pure inorganic substances. While both Brooks et al. (2004) and Svenningsson et al. (2005) reported that experimental behavior was well predicted, for the most part, by the Zdanovskii, Stokes, and Robinson (ZSR) relation, Chan and Chan (2003) found that HULIS-AS and HULIS-NaCl mixtures take up more water at a given RH than their simple additive sum would suggest. They also found that the relative enhancement in water uptake increased as RH decreased. For a 1:1 HULIS-AS mixture, the water uptake enhancement factor reached as much as 2.4 at $\mathrm{RH}=0.4$, while for HULIS$\mathrm{NaCl}$ mixtures, the extent of enhancement was maximally about 1.8 at an RH of 0.5. There was also some hint of a maximum in water uptake enhancement at some interim RH (40$50 \%$ ). Non-additive enhanced growth behavior has been previously reported for mixtures of different organic compounds with AS. However, the pattern of enhancement behavior as a function of RH was very different for the small, well defined organic acids studied (malonic, succinic, glutaric, citric, pinonic) (Chan and Chan 2003). For those compounds in mixtures with AS, relative enhancement decreased linearly with decreasing $\mathrm{RH}$, in contrast to increasing enhancement with decreasing RH for HULIS. The authors did not have an explanation for these unusual trends for HULIS:inorganic salt mixtures. 


\subsection{Droplet activation}

As far as we know, only one study to date has examined droplet activation of aerosol-derived HULIS (Dinar et al., 2006). Activation of particles made up of atmospheric HULIS extracted from fresh biomass burning, slightly aged biomass burning, and urban pollution aerosol particles was compared to activation of size-fractionated fulvic acid from an aquatic source (SRFA). HULIS was extracted from aerosol particles by an isolation procedure developed on the basis of the scheme used by the IHSS for fulvic and humic acid extraction from solids, as discussed earlier. The idea behind the size fractionation of SRFA was to prepare fractions enriched in smaller molecular weight components that could potentially be closer in size and character to HULIS. A correlation was found between cloud condensation nuclei (CCN)-activation diameter of SRFA fractions and number average molecular weight $\left(\mathrm{MW}_{\mathrm{N}}\right)$ of the fraction. The lower molecular weight fractions activated at lower critical diameters, which was explained by the greater number of solute species in the droplet for fractions of lower molecular weight. The three aerosol-extracted HULIS samples activated at lower diameters than any of the size-fractionated or bulk SRFA. For example, at a supersaturation of $0.2 \%$, the smallest SRFA fractions $\left(\mathrm{MW}_{\mathrm{N}}=440,520\right.$ and $\left.600 \mathrm{Da}\right)$ activated at sizes between 170 to $160 \mathrm{~nm}$, while aerosol HULIS extracts $\left(\mathrm{MW}_{\mathrm{N}}=410,500\right.$, and $\left.610 \mathrm{Da}\right)$ activated at 80,100 , and $135 \mathrm{~nm}$, respectively. Thus these aerosol HULIS were found to be substantially more $\mathrm{CCN}$-active than even the smallest size fractions of SRFA. HULIS extracted from the daytime smoke sample was more $\mathrm{CCN}$-active than the HULIS extract of fresh nighttime smoke particles. This was suggested to result from photochemical processing during the day time, mainly by OH-radicals, ozone and possibly UV, which led to enhanced degradation of the HULIS compounds and a decrease of its average molecular weight (Dinar et al., 2006).

\subsection{Surface and colloidal properties}

Like humic substances, HULIS have been found to be surface active (Facchini et al., 2000; Kiss et al., 2005; Dinar et al., 2006). Therefore, HULIS could enhance cloud droplet activation by depressing surface tension and lowering the critical supersaturation for activation (Gorbunov et al., 1998; Nenes et al., 2002), or alternatively, delay droplet activation due to hinderance of water vapor diffusion through a surface organic film (Chen and Lee, 1999; Rudich, 2003; Broekhuizen et al., 2004).

Facchini et al. (2000) observed a decrease in surface tension as a function of increasing TOC content in both aerosol and fog water samples from the Po Valley. Surface activity of the fog water fractionated into neutral, mono-and dicarboxylic acid (MDA), and polyacidic (HULIS) fractions according to Decesari et al. (2000) was also tested. The poly- acidic (HULIS) fraction was three times more surface active than the MDA fraction, and ten times more active than the neutral fraction. This was taken to be evidence for the humiclike character of the polyacidic fraction. It also corresponds to the general rule that higher polarity molecules (e.g., monoand di-carboxylic acids) have a greater affinity for the bulk solution and hence reduced surface-active properties (Negre et al., 2002).

HULIS extracted according to the method of Varga et al. (2001) from rural aerosol collected over different seasons was evaluated for surface activity effects at different aqueous concentrations representing estimated concentrations in droplets at the time of activation (Kiss et al., 2005). At $1 \mathrm{~g} / \mathrm{L}$, HULIS decreased the surface tension of water by $25-42 \%$, with the greatest decrease in surface tension for summer aerosol samples, and the smallest decrease for winter aerosol samples. No difference in bulk elemental composition was observed for the different samples. Surface tension lowering was enhanced in the presence of high concentrations of ammonium sulfate. The surface activity of HULIS samples generally was found to exceed that of humic acid samples and aqueous fulvic acid standards obtained from the IHSS at the same concentration. Dinar et al. (2006) also found that HULIS derived from biomass burning smoke aerosol particles, slightly aged smoke particles, and daytime urban aerosol particles lowered the surface tension of water more than did the fulvic acid standard (SRFA) at comparable solution concentrations.

Humic substances can dissolve or precipitate in aqueous solution, can accumulate at interfaces, can form selfassemblages, can solubilize organic compounds, and can exist in different colloidal states, depending on the solution composition (Tombacz 1999). Important humic molecule parameters that affect colloidal properties include functional group density, molecular size, and polydispersivity, all of which dictate the amphiphilic character of the humic material (Hayase and Tsubota, 1983; Engebretson and von Wandruszka, 1998; Kawahigashi and Fujitake, 1998; Yates and von Wandruszka, 1999). The most important solution parameters controlling colloidal behavior are $\mathrm{pH}$, ionic strength, and the presence of divalent or polyvalent metal cations (Engebretson and von Wandruszka, 1998; Yates and von Wandruszka, 1999). Polyvalent cations have a major influence on formation of humic micelle-like structures ("pseudomicelles") via their ability both to neutralize negative charges on the humic substances and to engage in bridging interactions (Yates and von Wandruszka, 1999). The higher the charge on the metal ion, the fewer needed to produce amphiphilic species that can migrate to an interface. Yet at higher metals concentrations, the bridging ability of the polyvalent cations can result in formation of pseudomicelles in solution, causing amphiphilic species to leave the interface (Yates and von Wandruszka, 1999). As such, curves of humic solution surface tension versus metal concentration, and surface tension versus $\mathrm{pH}$, have been found to feature 
a minimum in tension at intermediate metals concentrations and $\mathrm{pH}$ values (Yates and von Wandruszka, 1999). Humic pseudomicelles formed in solution have been reported to sequester hydrophobic organic species (Engebretson and Von Wandruszka, 1994; Engebretson et al., 1996).

Beyond the surface tension measurements reviewed above, and indirect evidence for metals complexing (Spokes et al., 1996; Gelencser et al., 2000c), there is little data in the literature about such colloidal qualities HULIS. Analytical interferences in anodic stripping voltammetry were exploited in a study of complexation of $\mathrm{Cu}$ with fog water by Gelencser et al. (2000c) to infer something about the presence of metalcomplexing HULIS in fog water. Humic substances interfere with anodic stripping voltammetry because the metalhumic complexes are electrochemically labile, meaning they undergo dissociation reactions during measurements and/or adsorb at the electrode surface. These interferences are manifested as shifts in peak current potential and peak width, as well as elevated baselines. In the study by Gelencser et al. (2000c), the voltammogram of fog water, with a certain natural $\mathrm{Cu}$ content, had a shifted and broader $\mathrm{Cu}$ peak and steeper baseline than a pure $\mathrm{Cu}$ solution. Upon $\mathrm{Cu}$ addition to the fog water, the $\mathrm{Cu}$ peak did not increase in size, but experienced an additional slight anodic shift and peak broadening. A second addition of $\mathrm{Cu}$ resulted in a split peak, with a reduction in the principal $\mathrm{Cu}$ peak and establishment of a very broad low intensity peak, more cathodic than the first, indicative of formation of a range of electroactive $\mathrm{Cu}$ organic complexes, similar to those observed for natural organic complexes like fulvic and humic acid. Though not suitable for quantitative characterization of natural complexants, the observed interferences were suggested to provide indirect evidence that natural complexants similar to fulvic and humic acid are present in the fog water in significant amounts. An earlier study (Spokes et al., 1996) used cathode stripping voltammetry in a similar manner to demonstrate $\mathrm{Cu}$ complexation by organic ligands in rain water. There, the concentration of organic ligands was found to be about twice the concentration in seawater.

If HULIS have similar colloidal and metals binding properties as humic substances, it could have important implications for the atmospheric chemistry of aerosols. This was discussed in a recent paper by Tabazadeh (2005). For example, at solution concentrations above the critical micelle concentration (CMC), humic pseudomicelles could potentially increase light scattering by aerosol particles due to increased solution turbidity. Micelle formation could also affect water uptake by the aerosol particle since the ionic composition will change when aggregates are formed in solution. The effect of amphiphilic substances on surface tension lowering will terminate at the CMC, as surface active species form micelles in the bulk solution rather than migrate to the air-solution interface. HULIS pseudomicelles could, in theory, solubilize hydrophobic organic pollutants, which could potentially protect organic pollutants from oxidation
(Tabazadeh 2005). Considering its possible importance to atmospheric chemistry, the colloidal nature of HULIS deserves more study. Based on data for humic substances (von Wandruszka, 1998; Yates and von Wandruszka, 1999; Negre et al., 2002), it can be suggested that at relevant atmospheric pH values (3-6 pH units; Facchini et al., 1999), the surface tension lowering capacity of HULIS may be at its greatest.

\section{Suggested origins of HULIS}

Potential origins of HULIS in the atmosphere are diverse, including primary terrestrial (Simoneit, 1980) and marine sources (Cini et al., 1994; Cini et al., 1996; Calace et al., 2001; Cavalli et al., 2004), biomass burning (Mukai and Ambe, 1986; Facchini et al., 1999; Zappoli et al., 1999; Graham et al., 2002; Mayol-Bracero et al., 2002), and secondary organic aerosol formation (condensation, reaction, oligomerization, etc.) (Gelencser et al., 2002; Jang et al., 2002; Jang et al., 2003; Tolocka et al., 2004; Hung et al., 2005). Different suggested mechanisms for HULIS generation during biomass burning include: (i) soil-derived humic matter lofted into the air as a result of combustion; (ii) HULIS generation via chemical transformations during combustion and thermal breakdown of plant lignins and cellulose; and (iii) recombination and condensation reactions between volatile, low molecular weight combustion products (Mayol-Bracero et al., 2002).

For the most part, terrestrial sources are not considered to be the origin of the bulk of HULIS in atmospheric aerosol. This is because most studies in the last decade have focused on HULIS derived from the WSOC fraction, which is prevalent mainly in fine mode aerosol (Cavalli et al., 2004; Yu et al., 2004). A primary marine source for HULIS has been championed by Cavalli et al. (2004) in a study of marine aerosol collected on the west coast of Ireland, and by Cini et al. $(1994,1996)$ for the origin of fulvic acids in Antarctic snow. For aerosol particles from Mace Head, Ireland, fine mode WSOC, including a HULIS fraction of about $27 \%$, was suggested to be derived from bubble-bursting at the ocean surface, which transfers organic matter into marine aerosol particles (Cavalli et al., 2004). The fulvic acid-like surface active fluorescent organic matter found in Antarctic snow was likewise enriched in the fine fraction, and was explained in terms of transport of aerosolized marine water (Cini et al., 1996).

Most other studies have proposed various secondary formation pathways for HULIS. For example, Gelencser et al. (2002) suggested that atmospheric HULIS is formed by evaporation, condensation, and aerosol-phase polymerization of polar, low molecular weight degradation products of organic debris in soil and other anthropogenic and natural sources. Their theory was based on a comparative study of the chemical structure of bulk organic matter in fine aerosol and natural humic and fulvic acids and involved simplified 
mass flux calculations with estimated air-water equilibrium data.

Soot oxidation as a source of HULIS was put forward by Decesari et al. (2002). They found that ozonolysis of soot creates a polyacidic WSOC fraction which they likened to HULIS reported in atmospheric aerosol particles. Since the ${ }^{1} \mathrm{H}$-NMR spectra of the oxidized soot-derived polyacidic fraction did not resemble the ${ }^{1} \mathrm{H}-\mathrm{NMR}$ spectra reported for aerosol and fog-water derived polyacidic fraction (Fig. 3), this mechanism cannot account for the whole variety of HULIS reported in atmospheric samples.

Based on analogy to formation of humic substances in soil, whereby polymerization reactions of small phenolic compounds released during metabolic processes are among the major chemical processes involved in synthesis of soil humic substances, Gelencser et al. (2003) suggested that atmospheric HULIS may be formed by in-cloud processing via similar reactions. They claimed that such liquid phase reactions could take place between a multiplicity of different polar aromatic compound precursors with hydroxyl radicals, yielding humic-like substances as secondary aerosol constituents. Such a mechanism implies that most aerosol particles are entrained at some point in their lifetime in clouds.

A number of laboratory studies have focused on elucidating photochemical and oxidative processes that could lead to the formation of HULIS and large macromolecules in atmospheric aerosol particles. These studies range from large simulation experiments (smog chambers) to flow tube studies, and invoke polymerization and oligomerization reactions for formation of secondary organic aerosol in the presence and absence of seed acid particles. Some of these studies are reviewed in the next section.

\section{Laboratory studies on the formation of HULIS}

In laboratory experiments, Gelencser et al. (2003) demonstrated the irreversible formation of HULIS in aqueous solution by means of Fenton reaction to produce $\mathrm{OH}$ radicals with 3,5-dihydroxybenzoic acid, as a model for aromatic mono/diacids. On a time scale of hours to days, brown products were formed, which were characterized by UVVIS spectrophotometry, liquid chromatography, ESI-mass spectrometry, thermally-assisted hydrolysis, methylationgas chromatography/mass spectrometry (THM-GC/MS), and thermal profiling (Hoffer et al., 2004). The features observed by all the analytical techniques closely resemble those found for natural humic materials and aerosol HULIS. The formed substances showed intense absorption in the lower visible to UV range, such that they may be important in atmospheric absorption of solar radiation. The electrospray ionization mass spectra of the entire reaction mixture exhibited a semicontinuous distribution of ions up to about $m / z=500$. It was concluded that the reaction products consist of a large number of species of different molecular weights, well below
$1000 \mathrm{Da}$, analogous to the findings for HULIS isolated from urban and rural aerosol particles (Havers et al., 1998; Kiss et al., 2003). Liquid chromatography identified a number of new compounds covering a wide range of polarity. The abundance of low molecular weight compounds led the authors to conclude that the reaction proceeds by oligomerization rather than polymerization. As the time of the reaction proceeded to a maximum of 7 days, thermal profiles clearly showed the development of more refractory substances.

Experiments with acidic seed aerosol particles have shown an increased formation of secondary organic aerosol (SOA) mass, with formation of high molecular weight products, compared to non-acidic aerosol (Jang et al., 2002). It was suggested that acid-catalyzed chemical reactions, such as aldol condensation and gem-diol reactions of biogenicallyemitted compounds, can lead to the formation of high molecular weight oligomers which may affect the physical and chemical properties of organic particles (Jang et al., 2002; Jang et al., 2003; Tolocka et al., 2004). The chemical reactions include diverse acid-catalyzed reactions such as hydration, polymerization, hemiacetal and acetal formation, aldol condensation, ring opening of terpenoid carbonyls, and cross-linking in the particle phase. Specific functional groups that lead to these reactions include aliphatic aldehydes and carbonyls. For example, it was found that glyoxal, an unlikely SOA precursor by virtue of its high vapor pressure, can form high molecular weight products because of its highly reactive $\alpha$-dicarbonyl functionality. Isoprene oxidation products may also participate in such chemistry (Jang et al., 2002; Tolocka et al., 2004). The formation of these compounds is relatively effective, leading to positive deviations from the expected partition coefficient of carbonylcontaining and other semivolatile compounds. A good example is the partition of 2-hydroxy-1,3-propanedial into the condensed phase of SOA which is three orders of magnitude higher than can be predicted by its $K_{p}$ due to the acidcatalyzed heterogeneous reactions that consume it (Jang et al., 2002). Limbeck et al. (2003) also presented evidence for efficient SOA formation in an acidic medium by means of irreversible formation of HULIS in heterogeneous reactions of dienes (i.e., isoprene) in the presence of sulfuric acid. The humic-like character of the reaction products was evidenced by UV-spectrometry, thermal analysis, and FTIR diffuse reflectance spectroscopy. In addition, Iinuma et al. (2004) studied SOA formation by ozonolysis of $\alpha$-pinene in the presence of acidic particles. Thermographic TOC determination showed an increase of particle phase organics by $40 \%$ in the presence of sulphuric acid seed particles. Capillary electrophoresis ESI-MS analysis showed formation of compounds with $\mathrm{MW}_{\mathrm{M}}>300$, with HULIS character.

It is expected that acidic aerosols such as $\mathrm{H}_{2} \mathrm{SO}_{4}$ and $\mathrm{HNO}_{3}$ could provide sites for such photochemical reactions in the atmosphere. Diesel soot, due to its $\mathrm{H}_{2} \mathrm{SO}_{4}$ content, is also expected to provide enough acidity for acid-catalyzed reactions. It was found that acid-catalyzed reactions can 
occur even on wood burning soot, which has low sulfur content, suggesting that even small amounts of acid can have a profound effect (Jang et al., 2002; Jang et al., 2003).

Kalberer et al. (2004) demonstrated polymerization reactions during the photoxidation of 1,3,4-trimethylbenzene (TMB) over the course of about $20 \mathrm{~h}$ in a large photochemical chamber. They measured a large number of compounds with molecular weight up to $1000 \mathrm{Da}$ by laser desorption ionization (LDI) mass spectrometry. Peaks between 400 and $900 \mathrm{Da}$ showed a highly regular mass difference of 14,16 and $18 \mathrm{Da}$, suggesting that polymerization reactions were responsible for the SOA formed in the reaction chamber. It was suggested that the basic units correspond to glyoxal and pyruvic acid. The proposed reaction mechanism is a nonradical-induced acetal polymerization with methylglyoxal as the main monomer, though other carbonyls, carbonylcontaining acids and hydrated carbonyls can also be incorporated into the products (Kalberer et al., 2004). However, if other units play a role in the reaction mechanisms, it might be more difficult to explain the regular spacing observed in the products. The polymer formed has a $\mathrm{O} / \mathrm{C}$ ratio close to 1 , which is rather higher than the ratio measured in ambient HULIS (Krivacsy et al., 2001a; Kiss et al., 2002). In contrast to the experiments by Jang et al. (2002; Jang et al. 2003), the polymerization reaction demonstrated by Kalberer et al. (2004) occurs without the use of acidic seed particles. It was suggested that the acidity produced by the organic acids suffices to promote the reaction. The same products, with higher formation rates, were observed when the reactions were carried out under realistic atmospheric concentrations, presumably due to the higher surface to volume ratios of the smaller particles that formed in these experiments (Kalberer et al., 2004).

In a series of photochemical chamber experiments, Gao et al. (2004a, b) further studied the effect of acidity on oligomer formation. Using acidic and basic seed aerosols, they studied SOA formation from ozonolysis of several precursors ( $\alpha$-pinene, cyclohexene, 1-methyl cyclohexene, 1methyl cyclopentene, cyclopoctene, 1-methyl cyclohexene and terpinolene). Products up to $1600 \mathrm{Da}$ were observed using liquid chromatography - ion trap mass spectrometry. The high molecular mass peak intensities compare to, or sometimes exceed, the peak intensities of low molecular mass $(<250 \mathrm{Da})$ species. It was found that while basic conditions lead to oligomer formation, higher acidity in the seed particles resulted in faster and larger oligomer formation and higher overall SOA yield (Gao et al., 2004b). It was also suggested that the precursor hydrocarbon structure, substitution and isomeric structures can affect the type of SOA formed due to both gas-phase and aerosol-phase reaction pathways (Gao et al., 2004a).

High molecular weight products were detected in the ozonolysis of oleic acid-coated particles (Katrib et al., 2004). Using HPLC-MS methods, it was shown that the oligomers (often exceeding $1000 \mathrm{Da}$ ) exhibit regular spacing of 189 and
$172 \mathrm{Da}$ (Hung et al., 2005). The regular spacing of $172 \mathrm{Da}$ (9-oxononanoic acid) and $188 \mathrm{Da}$ (azelaic acid Criegee intermediate) in the mass spectra suggest that these species are the monomers in condensed-phase polymerization reactions (Hung et al., 2005). It was postulated that 9-oxononanoic acid lengthens the molecular chain via secondary ozonide formation; the azelaic acid Criegee intermediate links molecular units via ester formation (specifically, $\alpha$-acyloxyalkyl hydroperoxides). High molecular weight molecules also formed in the reaction of oleic acid with the nitrate radical (Hung et al., 2005). Other types of high molecular weight species, mostly involving 5 and 6 oxygen-containing rings, were detected by photoelectron resonance capture ionization-aerosol mass spectrometry (Zahardis et al., 2005). Formation of hydroperoxy products in the ozonolysis of oleic acid particles was demonstrated also by thermal desorption mass spectrometry (Ziemann, 2005). It is worth noting that although these laboratory studies used pure oleic acid particles, which do not represent real SOA, the proposed reaction mechanism can operate in real atmospheric particles as the participating functional groups are abundant in real SOA. The proposed reaction mechanism by Katrib et al. (2004) and by Ziemann et al. (2005) do not require acidity for production of high molecular weight products.

These laboratory studies have identified possible atmospheric pathways for the formation of high molecular weight species in oxidation reactions which involve reactions in the condensed phase. For example, polycarboxylic aromatic acids can be formed by the oxidation of soot by ozone (Decesari et al., 2002), aromatic acids and phenols can be formed via polymerization of aromatic acids and carbonyls in the liquid phase by $\mathrm{H}_{2} \mathrm{O}_{2}$ (Gelencser et al., 2003), and polyhydroxy-aliphatic compounds and polyethers can be formed by polymerization of aliphatic carbonyls (Jang et al., 2003).

The results of these studies imply that due to oligomerization and polymerization reactions, models that assume phase partition of gas phase molecules based only on solubility, may lead to large errors due to the reactive uptake of semi-volatile species by aerosol particles (Jang et al., 2002; Kalberer et al., 2004). This raises the need to provide better estimates of the products' molecular weights as well as the actual SOA density in order to achieve good mass closure in SOA formation (Gao et al., 2004a).

A major difficulty arises because it is not straightforward to compare the characterization methods used in laboratory studies with those used for analysis of collected aerosol particles. In general it can be claimed that the spectra of the high molecular weight species in laboratory-generated SOAs extend to higher masses, and exhibit more regular structure, pointing to polymerization reactions. This may be attributed to the more simplified chemical mixture and aerosol matrices in which these reactions occur compared to the real atmosphere. The difference may also result from the fact that some of the products probed are not necessarily water solu- 
ble, which is the fraction most often studied in collected particles. Results obtained from more gentle ionization methods are suggestive that traditional methods for characterizing the organic content of atmospheric aerosol particles may have overestimated the amount of low molecular weight species, as these may sometimes form by disintegration of higher molecular weight species during characterization.

\section{Amounts and seasonal distribution of HULIS}

WSOC derived from continental aerosol particles obtained from a remote mountain site in China ( $\mathrm{Li}$ et al., 2000) and marine and continental aerosol from coastal Hong Kong (Yu et al., 2004) displays a bimodal fine and coarse mode distribution, dominated by the fine (accumulation) mode (about $70 \%$ ). On the basis of thermal profiling, coarse mode WSOC was found to be comprised mainly of low molecular weight compounds (Yu et al., 2004), while approximately $40 \%$ of the fine mode WSOC was estimated to consist of high molecular weight polar compounds. Marine aerosol particles from Mace head, Ireland, however, showed co-equal fractions of HULIS in coarse and fine mode WSOC (22 and 27\%, respectively), although altogether WSOC made up only $2 \%$ of coarse mode aerosol particle and $15 \%$ of fine mode aerosol particles (Cavalli et al., 2004).

In general, the estimated fraction of HULIS out of fine mode WSOC can be quite variable, ranging, for example, from a low of 15 to $36 \%$ in Amazon biomass burning aerosol (Mayol-Bracero et al., 2002) to a high of 55 to $60 \%$ in European fine aerosol (Krivacsy et al., 2001b). Other estimates for aerosol and fog water HULIS fall within this range: HULIS making up 32 to $50 \%$ of WSOC in fog water $(<1.5 \mu \mathrm{m}$ droplet size) (Facchini et al., 1999), 29-42\% of WSOC in atmospheric fine aerosol (Decesari et al., 2001a), and 20-50\% of WSOC in European fine aerosol (Zappoli et al., 1999). Such broad ranges also encompass the early report by Likens and Galloway (1983) of 42-54\% macromolecular organic carbon out of total DOC in rural northeast USA precipitation.

Aerosol total carbon (TC) concentration in fine aerosol collected in the Po Valley follows the same annual trend of the aerosol inorganic ion constituents, characterized by lower values during the summer months and higher values in winter (Decesari et al., 2001b). The WSOC concentration exhibited an annual periodicity similar to that of TC and aerosol inorganic constituents. Polycarboxylic acids (HULIS) were the most abundant class of compounds of the WSOC fraction in spring, fall, and winter, but not in summer, such that HULIS concentration was found to be correlated to anthropogenic emissions (Decesari et al., 2001b).

Seasonal differences in HULIS chemistry were reported by Duarte et al. (2005), who showed that the relative aromaticity of HULIS as determined by ${ }^{13} \mathrm{C}$-NMR was greater in autumn samples than in summer samples. This was at- tributed to a greater contribution from lignin breakdown products due to wood combustion processes (Duarte et al., 2005). Samburova et al. (2005b) likewise observed seasonal differences in urban aerosol particle composition (Zurich), also attributed to wood combustion during the winter months and photochemical production during the summer months.

Considering base-extracted humic-like materials, humic acid carbon was found to represent $6-11 \%$ of total organic carbon in urban dust (Havers et al., 1998), 1-6\% of total organic carbon in rural dust (Mukai and Ambe, 1986), and $0.5-2.2 \%$ of the total dust mass in aeolian dust (Simoneit, 1980).

\section{Atmospheric HULIS: How humic-like are they?}

The particularly small molecular size attributed to HULIS in atmospheric samples as compared to fulvic acids and to laboratory-generated macromolecular species, requires certain contemplation. First, it may be asked if atmospheric HULIS truly can be considered macromolecular species. This question may be part of a larger issue currently debated in the humic substances literature involving a new model for humic substances structure, whereby humic substances are considered to consist of supramolecular associations rather than macromolecular polymers (Piccolo et al., 1996a; Piccolo et al., 1996b; Conte and Piccolo, 1999; Piccolo et al., 1999; Piccolo and Conte, 2000; Cozzolino et al., 2001; Piccolo, 2001; Piccolo et al., 2001; Piccolo, 2002; Piccolo et al., 2003; Peuravuori and Pihlaja, 2004). The new conceptual model suggests that small and heterogeneous humic molecules self-assemble into supramolecule conformations stabilized mainly by weak forces such as van der Waals, $\pi-\pi$, or $\mathrm{CH}-\pi$ bonds. These weakly bound conformations are believed to have only apparent large molecular dimensions, which can be reversibly disrupted into smaller molecular associations when treated with organic acids. In particular, mono- and dicarboxylic acids have been reported to have a maximal disaggregating effect (Piccolo et al., 1996a; Piccolo et al., 2003). Inorganic acids, phenol, and alcohols do not produce the same decrease in apparent size of humic substances (Piccolo et al., 1996b). Size distributions of true polymers such as polysaccharides and polystyrene sulphonates do not change upon addition of organic acids (Piccolo, 2001; Piccolo et al., 2001). More details concerning this model may be found in a recent review (Sutton and Sposito, 2005). If the suprastructure model for terrestrial humic substances is correct, the high mono-and dicarboxylic organic acid content as well as the inorganic acid content of atmospheric aerosols (Fuzzi et al., 2002; Graham et al., 2002; Mayol-Bracero et al., 2002; Falkovich et al., 2005) may actually prevent formation of larger humic suprastructures, explaining the observed low molecular weights for HULIS in field collected particles (Krivacsy et al., 2000; Cappiello et al., 2003; Kiss et al., 2003; Samburova 
et al., 2005a). Thus, this model, combined with recent ESIMS results for SEC fractionated fulvic acids (Reemtsma and These, 2003), TEM results for humic acids (Baalousha et al., 2005), and two-dimensional diffusion-ordered spectroscopy (DOSY) NMR experiments at different concentrations of humic acids (Simpson, 2002) may shed some interesting light on the small molecular size reported for atmospheric HULIS as contrasted with fulvic and humic acids.

There are alternative explanations for the relatively small size of atmospheric HULIS. First, UV radiation is well known to degrade humic substances in lake waters, resulting in humic molecules of smaller size, formation of low molecular weight organic compounds, and formation of inorganic carbon in the form of $\mathrm{CO}_{2}$ (Dehaan, 1993; Molot and Dillon, 1997; Gennings et al., 2001; Osburn et al., 2001; Molot et al., 2005). Similarly, ozonolysis cleaves bonds in humic substances, reducing their molecular size substantially (Anderson et al., 1986; Feng et al., 1992; Ohlenbusch et al., 1998; Myllykangas et al., 2002; Jung and Choi, 2003; Swietlik et al., 2004). Ozonolysis involves oxidation of aromatic and conjugated double bond moieties for all humic molecular weight fractions (Ohlenbusch et al., 1998; Myllykangas et al., 2002; Slavinskaya and Selemenev, 2003; Swietlik et al., 2004), and formation of low molecular weight carboxylic acids (Myllykangas et al., 2002; Swietlik et al., 2004), oxyacids (Xiong et al., 1992) and aldehydes (Xiong et al., 1992). Finally, hydroxyl radicals also enhance degradation of humic substances (Gjessing and Kallovist, 1991; Pullin et al., 2004; Molot et al., 2005). Considering the reactivity of humic substances in the face of $\mathrm{UV}$ radiation, $\mathrm{O}_{3}$ and hydroxyl radicals, it can be anticipated that conditions in the atmosphere are such that relatively larger macromolecules, even if formed, cannot be long-lived. HULIS, then, may represent some non-equilibrium phase resulting from a quasi- steady state between formation and destruction of larger species.

Yet another alternative to the small size conundrum is that HULIS, or, at least, HULIS obtained from water extracts, consists mainly of a complex, unresolved mixture of relatively small molecules rather than a mixture of complex macromolecular entities. The apparent similarity of HULIS to humic substances would then be a fortuitous outcome of the difficulty in comparing spectra of unresolved mixtures of compounds. The evidence for such a claim may lie in the ultrafiltration behavior of HULIS, which, with the exception of precipitation studied by Likens and Galloway (1983), has been found to pass in its entirety through ultrafiltration membranes of 500 and 1000 Da (Havers et al., 1998; Krivacsy et al., 2001a; Kiss et al., 2003). Such behavior stands in stark contrast to the ultrafiltration behavior of many different fulvic and humic acids, which have been shown in numerous works to be rejected in large proportion by ultrafiltration membranes with a nominal cutoff of $1000 \mathrm{Da}$ (Aiken, 1984; Marley et al., 1992; Aoustin et al., 2001; Alberts and Takacs, 2004; Assemi et al., 2004; Peuravuori et al., 2005; Schwede-Thomas et al. 2005) (and many others). Part of the discrepancy may lie in the different methodologies commonly applied for extraction and isolation of HULIS. In studies where HULIS from aerosol particles was extracted using traditional soil science methods, apparent molecular sizes are relatively larger. For example, gel permeation chromatography applied to aerosol humic acid extracts gave a molecular size range of 500-10000 Da compared with polyethylene standards (Mukai and Ambe, 1986), while Subbalakshmi et al. (2000) isolated their base extracted, acid precipitated humic acid from air particulate matter in $12-14 \mathrm{kDa}$ dialysis tubing. It is also worth contemplating why mass spectral studies of secondary aerosol formation in laboratory settings reveal polymeric materials with repeating mass units (Hung et al., 2005), while similar studies of aerosol HULIS demonstrate extremely complex mass spectra with no apparent repeating units.

The very different modes of formation and the duration of formation for HULIS as compared with humic terrestrial/aquatic humic substances may also account for the relatively small size of HULIS, as well as many of the other observed differences. A general consensus views terrestrial/aquatic humic substances as formed via a multistage process involving microorganism-mediated decomposition of plant biopolymers (lignin, cellulose, etc.) into simpler monomers and oligomers, repeated biogenic metabolism and recycling of the smaller compounds, and concurrent polymerization of reactive hydroxyquinones, polyphenols and other compounds, into higher molecular weight humic macromolecules (Stevenson, 1994). Such processes require extensive periods of time and essential involvement of microorganisms. Considering that the major portion of HULIS is believed to be of secondary atmospheric origin driven by abiotic oxidizing reactions over a short time scale, it should not perhaps come as a surprise that HULIS is smaller and apparently less aromatic than terrestrial and aquatic humic substances.

It is also possible that some of the differences between HULIS and humic substances stem from the extraction and isolation methods utilized, or from the not-uncommon practice of analyzing whole WSOC or even whole aerosol samples for various chemical tests. Thus, a major goal of further research in the field should be an inter-comparison between isolation methods and establishment of a standardized approach to HULIS extraction and isolation, with more realistic comparisons between laboratory and field studies. To now, the majority of studies of HULIS involves only the water soluble fraction, and excludes the base-soluble and insoluble fractions of humic substances. Thus, characterization of the water insoluble organic fraction is highly desirable, as well as a comparative characterization of HULIS derived from different sources. Likewise lacking in the literature is information regarding HULIS colloidal properties, micellular or pseudo-micellular behavior, metals and organic contaminant binding abilities in both the solid and liquid phase, and acidity constants. In part, the lack of such information is 
a result of the difficulty of sampling and extracting sufficient amounts of material for such investigations.

Summarizing all the data reviewed above, we find that the polyacidic nature of HULIS, including number of $\mathrm{COOH}$ groups out of total OC groups is similar to that of fulvic acids. FTIR spectra of WSOC-derived HULIS are likewise very similar to those of some aquatic fulvic acids. Dissimilarities between HULIS and fulvic acids include greater surface activity, smaller droplet activation diameters, smaller molecular size, lower aromaticity, higher $\mathrm{H} / \mathrm{C}$ molar ratios, and weaker acidic nature for HULIS. It should be recalled that a relatively small number of HULIS samples have been studied and characterized to now, and that the different extraction and isolation schemes that have been employed are expected to have an influence on the physical and chemical properties of the extracted product. Therefore, these apparent differences and similarities may change as our information grows. Nevertheless, it does seem possible to conclude that humic acids are not good models for WSOC-derived HULIS. Also, fulvic acids do not always show the same behavior as HULIS in certain atmospherically-important situations, such as droplet activation. No such comparisons between humic substances and HULIS extracted from non-water soluble organic carbon can be drawn, as there are hardly any studies of this fraction.

Acknowledgements. Support from the Israel Science Foundation (grant \#162/05) has enabled the writing of this review.

Edited by: S. Martin

\section{References}

Aiken, G., McKnight, D. M., Wershaw, R. L., and MacCarthy, P.: An introduction to humic substances in soil, sediment, and water, in: Humic Substances in Soil, Sediment, and Water, edited by: Aiken, G. R., McKnight, D. M., Wershaw, R. L., and MacCarthy, P., John Wiley \& Sons, New York, 1-9, 1985.

Aiken, G. R.: Evaluation of ultrafiltration for determining molecular weight of fulvic acid, Environ. Sci. Technol., 18, 978-981, 1984.

Aiken, G. R.: Isolation and characterization techniques for aquatic humic substances, in: Humic Substances in Soil, Sediment, and Water, edited by: Aiken, G. R., McKnight, D. M., Wershaw, R. L., and MacCarthy, P., John Wiley \& Sons, New York, 363-386, 1985.

Aiken, G. R., McKnight, D. M., Thorn, K. A., and Thurman, E. M.: Isolation of hydrophilic organic acids from water using nonionic macroporous resins, Org. Geochem., 18, 567-573, 1992.

Aiken, G. R., Thurman, E. M., and Malcolm, R. L.: Comparison of XAD Macroporous Resins for the Concentration of Fulvic Acid from Aqueous Solution, Anal. Chem., 51, 1799-1803, 1979.

Alberts, J. J. and Takacs, M.: Comparison of the natural fluorescence distribution among size fractions of terrestrial fulvic and humic acids and aquatic natural organic matter, Org. Geochem., 35, 1141-1149, 2004.
Anderson, L. J., Johnson, J. D., and Christman, R. F.: Extent Of Ozone Reaction With Isolated Aquatic Fulvic-Acid, Environ. Sci. Technol., 20, 739-742, 1986.

Andracchio, A., Cavicchi, C., Tonelli, D. and Zappoli, S.: A new approach for the fractionation of water-soluble organic carbon in atmospheric aerosols and cloud drops, Atmos. Environ., 36, 5097-5107, 2002.

Aoustin, E., Schafer, A. I., Fane, A. G., and Waite, T. D.: Ultrafiltration of natural organic matter, Separ. Purification Technol., 22-3, 63-78, 2001.

Assemi, S., Newcombe, G., Hepplewhite, C., and Beckett, R.: Characterization of natural organic matter fractions separated by ultrafiltration using flow field-flow fractionation, Water Res., 38, 1467-1476, 2004.

Baalousha, M., Motelica-Heino, M., Galaup, S., and Le Coustumer, P.: Supramolecular structure of humic acids by TEM with improved sample preparation and staining, Microsc. Res. Techniq., 66, 299-306, 2005.

Baker, A.: Fluorescence excitation-emission matrix characterization of some sewage-impacted rivers, Environ. Sci. Technol., 35, 948-953, 2001.

Beckett, R., Jue, Z., and Giddings, J. C.: Determination of molecular weight distribution of fulvic and humic acids using flow fieldflow fractionation, Environ. Sci. Technol., 21, 289-295, 1987.

Broekhuizen, K., Kumar, P. P., and Abbatt, J. P. D.: Partially soluble organics as cloud condensation nuclei: Role of trace soluble and surface active species, Geophys. Res. Lett., 31, L01107, doi:10.1029/2003GL018203, 2004.

Brooks, S. D., DeMott, P. J., and Kreidenweis, S. M.: Water uptake by particles containing humic materials and mixtures of humic materials with ammonium sulfate, Atmos. Environ., 38, 18591868, 2004.

Brown, T. L. and Rice, J. A.: Effect of experimental parameters on the ESI FT-ICR mass spectrum of fulvic acid, Anal. Chem., 72, 384-390, 2000a.

Brown, T. L. and Rice, J. A.: The effect of laser wavelength and power density on the laser desorption mass spectrum of fulvic acid, Org. Geochem., 31, 627-634, 2000b.

Calace, N., Petronio, B. M., Cini, R., Stortini, A. M., Pampaloni, B., and Udisti, R.: Humic marine matter and insoluble materials in Antarctic snow, Int. J. Environ. Anal. Chem., 79, 331-348, 2001.

Cappiello, A., De Simoni, E., Fiorucci, C., Mangani, F., Palma, P., Trufelli, H., Decesari, S., Facchini, M. C., and Fuzzi, S.: Molecular characterization of the water-soluble organic compounds in fogwater by ESIMS/MS, Environ. Sci. Technol., 37, 1229-1240, 2003.

Cavalli, F., Facchini, M. C., Decesari, S., Mircea, M., Emblico, L., Fuzzi, S., Ceburnis, D., Yoon, Y. J., O’Dowd, C. D., Putaud, J. P., and Dell'Acqua, A.: Advances in characterization of size-resolved organic matter in marine aerosol over the North Atlantic, J. Geophys. Res.-Atmos., 109, D24215, doi:10.1029/2004JD005137, 2004.

Chan, M. N. and Chan, C. K.: Hygroscopic properties of two model humic-like substances and their mixtures with inorganics of atmospheric importance, Environ. Sci. Technol., 37, 5109-5115, 2003.

Chen, Y. Y. and Lee, W. M. G.: Hygroscopic properties of inorganic-salt aerosol with surface-active organic compounds, Chemosphere, 38, 2431-2448, 1999. 
Chin, Y. P., Aiken, G., and Oloughlin, E.: Molecular-Weight, Polydispersity, And Spectroscopic Properties Of Aquatic Humic Substances, Environ. Sci. Technol., 28, 1853-1858, 1994.

Cini, R., Innocenti, N. D., Loglio, G., Oppo, C., Orlandi, G., Stortini, A. M., Tesei, U., and Udisti, R.: Air-sea exchange: Sea salt and organic micro components in Antarctic snow, Int. J. Environ. Anal. Chem., 63, 15-27, 1996.

Cini, R., Innocenti, N. D., Loglio, G., Stortini, A. M., and Tesei, U.: Spectrofluorometric Evidence Of The Transport Of Marine Organic-Matter In Antarctic Snow Via Air-Sea Interaction, Int. J. Environ. Anal. Chem., 55, 285-295, 1994.

Clark, C. D., Jimenez-Morais, J., Jones, G., Zanardi-Lamardo, E., Moore, C. A., and Zika, R. G.: A time-resolved fluorescence study of dissolved organic matter in a riverine to marine transition zone, Mar. Chem., 78, 121-135, 2002.

Conte, P. and Piccolo, A.: Conformational arrangement of dissolved humic substances. Influence of solution composition on association of humic molecules, Environ. Sci. Technol., 33, 1682-1690, 1999.

Cozzolino, A., Conte, P., and Piccolo, A.: Conformational changes of humic substances induced by some hydroxy-, keto-, and sulfonic acids, Soil Biol. Biochem., 33, 563-571, 2001.

Croue, J. P.: Isolation of humic and non-humic NOM fractions: Structural characterization, Environ. Monitor. Assess., 92, 193207, 2004.

Decesari, S., Facchini, M. C., Fuzzi, S., and Tagliavini, E.: Characterization of water-soluble organic compounds in atmospheric aerosol: A new approach, J. Geophys. Res.-Atmos., 105, 14811489, 2000.

Decesari, S., Facchini, M. C., Matta, E., Lettini, F., Mircea, M., Fuzzi, S., Tagliavini, E., and Putaud, J. P.: Chemical features and seasonal variation of fine aerosol water-soluble organic compounds in the Po Valley, Italy, Atmos. Environ., 35, 3691-3699, 2001a.

Decesari, S., Facchini, M. C., Matta, E., Lettini, F., Mircea, M., Fuzzi, S., Tagliavini, E., and Putaud, J. P.: Chemical features and seasonal variation of fine aerosol water-soluble organic compounds in the Po Valley, Italy, Atmos. Environ., 35, 3691-3691, $2001 b$.

Decesari, S., Facchini, M. C., Matta, E., Mircea, M., Fuzzi, S., Chughtai, A. R., and Smith, D. M.: Water soluble organic compounds formed by oxidation of soot, Atmos. Environ., 36, 18271832, 2002.

Dehaan, H.: Solar Uv-Light Penetration And Photodegradation Of Humic Substances In Peaty Lake Water, Limnol. Oceanog., 38, 1072-1076, 1993.

DeNobili, M. and Chen, Y.: Size exclusion chromatography of humic substances: limits, perspectives and prospects, Soil Sci., 164, 825-833, 1999.

Dinar, E., Taraniuk, I., Graber, E. R., Katsman, S., Moise, T., Anttila, T., Mentel, T. F., and Rudich, Y.: Cloud condensation nuclei properties of model and atmospheric HULIS, Atmos. Chem. Phys. Discuss., 6, 1073-1120, 2006.

Duarte, R., Pio, C. A., and Duarte, A. C.: Synchronous scan and excitation-emission matrix fluorescence spectroscopy of watersoluble organic compounds in atmospheric aerosols, J. Atmos. Chem., 48, 157-171, 2004.

Duarte, R., Pio, C. A., and Duarte, A. C.: Spectroscopic study of the water-soluble organic matter isolated from atmospheric aerosols collected under different atmospheric conditions, Analy. Chim. Acta, 530, 7-14, 2005.

Engebretson, R., Amos, T., and Von Wandruszka, R.: Quantitative approach to humic acid associations, Environ. Sci. Technol., 30, 990-997, 1996.

Engebretson, R. and Von Wandruszka, R.: Microorganization in dissolved humic acid, Environ. Sci. Technol., 28, 1934-1941, 1994.

Engebretson, R. B. and von Wandruszka, R.: Kinetic aspects of cation enhanced aggregation in aqueous humic acids, Environ. Sci. Technol., 32, 488-493, 1998.

Facchini, M. C., Decesari, S., Mircea, M., Fuzzi, S., and Loglio, G.: Surface tension of atmospheric wet aerosol and cloud/fog droplets in relation to their organic carbon content and chemical composition, Atmos. Environ., 34, 4853-4857, 2000.

Facchini, M. C., Fuzzi, S., Zappoli, S., Andracchio, A., Gelencser, A., Kiss, G., Krivacsy, Z., Meszaros, E., Hansson, H. C., Alsberg, T., and Zebuhr, Y.: Partitioning of the organic aerosol component between fog droplets and interstitial air, J. Geophys. Res.Atmos., 104, 26 821-26 832, 1999.

Falkovich, A. H., Graber, E. R., Schkolnik, G., Rudich, Y., Maenhaut, W., and Artaxo, P.: Low molecular weight organic acids in aerosol particles from Rondonia, Brazil, during the biomassburning, transition and wet periods, Atmos. Chem. Phys., 5, 781797, 2005.

Feng, J. S. and Moller, D.: Characterization of water-soluble macromolecular substances in cloud water, J. Atmos. Chem., 48, 217233, 2004.

Feng, X. O., Croue, J. P., and Legube, B.: Long-Term Ozone Consumption By Aquatic Fulvic-Acids Acting As Precursors Of Radical Chain-Reactions, Environ. Sci. Technol., 26, 10591064, 1992.

Francioso, O., Montecchio, D., Gioacchini, P., and Ciavatta, C.: Thermal analysis (TG-DTA) and isotopic characterization (C-13$\mathrm{N}-15$ ) of humic acids from different origins, Appl. Geochem., 20, 537-544, 2005.

Francioso, O., Sanchez-Cortes, S., Casarini, D., Garcia-Ramos, J. V., Ciavatta, C., and Gessa, C.: Spectroscopic study of humic acids fractionated by means of tangential ultrafiltration, J. Molecular Struct., 609, 137-147, 2002.

Fuzzi, S., Decesari, S., Facchini, M. C., Matta, E., Mircea, M., and Tagliavini, E.: A simplified model of the water soluble organic component of atmospheric aerosols, Geophys. Res. Lett., 28, 4079-4082, 2001.

Fuzzi, S., Facchini, M. C., Decesari, S., Matta, E., and Mircea, M.: Soluble organic compounds in fog and cloud droplets: what have we learned over the past few years?, Atmos. Res., 64, 89-98, 2002.

Gao, S., Keywood, M., Ng, N. L., Surratt, J., Varutbangkul, V., Bahreini, R., Flagan, R. C., and Seinfeld, J. H.: Low-molecularweight and oligomeric components in secondary organic aerosol from the ozonolysis of cycloalkenes and alpha-pinene, J. Phys. Chem. A, 108, 10 147-10 164, 2004a.

Gao, S., Ng, N. L., Keywood, M., Varutbangkul, V., Bahreini, R., Nenes, A., He, J. W., Yoo, K. Y., Beauchamp, J. L., Hodyss, R. P., Flagan, R. C., and Seinfeld, J. H.: Particle phase acidity and oligomer formation in secondary organic aerosol, Environ. Sci. Technol., 38, 6582-6589, 2004b.

Gelencser, A.: Carbonaceous Aerosol, Springer, Dordrecht, 2004. 
Gelencser, A., Hoffer, A., Kiss, G., Tombacz, E., Kurdi, R., and Bencze, L.: In-situ formation of light-absorbing organic matter in cloud water, J. Atmos. Chem., 45, 25-33, 2003.

Gelencser, A., Hoffer, A., Krivacsy, Z., Kiss, G., Molnar, A., and Meszaros, E.: On the possible origin of humic matter in fine continental aerosol, J. Geophys. Res.-Atmos., 107, D12 4137, doi:10.1029/2001JD001299, 2002.

Gelencser, A., Hoffer, A., Molnar, A., Krivacsy, Z., Kiss, G., and Meszaros, E.: Thermal behaviour of carbonaceous aerosol from a continental background site, Atmos. Environ., 34, 823-831, 2000a.

Gelencser, A., Meszaros, T., Blazso, M., Kiss, G., Krivacsy, Z., Molnar, A., and Meszaros, E.: Structural characterisation of organic matter in fine tropospheric aerosol by pyrolysis-gas chromatography-mass spectrometry, J. Atmos. Chem., 37, 173$183,2000 b$.

Gelencser, A., Sallai, M., Krivacsy, Z., Kiss, G., and Meszaros, E.: Voltammetric evidence for the presence of humic-like substances in fog water, Atmos. Res., 54, 157-165, 2000c.

Gennings, C., Molot, L. A., and Dillon, P. J.: Enhanced photochemical loss of organic carbon in acidic waters, Biogeochem., 52, 339-354, 2001.

Gjessing, E. T. and Kallovist, T.: Algicidal And Chemical Effect Of UV-Radiation Of Water Containing Humic Substances, Water Res., 25, 491-494, 1991.

Gorbunov, B., Hamilton, R., Clegg, N., and Toumi, R.: Water nucleation on aerosolparticles containing both organic and soluble inorganic substances, Atmos. Res., 47-48, 271-283, 1998.

Graham, B., Mayol-Bracero, O. L., Guyon, P., Roberts, G. C., Decesari, S., Facchini, M. C., Artaxo, P., Maenhaut, W., Koll, P. and Andreae, M. O.: Water-soluble organic compounds in biomass burning aerosols over Amazonia - 1. Characterization by NMR and GC-MS, J. Geophys. Res.-Atmos., 107, D20 8047, doi:10.1029/2001JD000336, 2002.

Gysel, M., Weingartner, E., Nyeki, S., Paulsen, D., Baltensperger, U., Galambos, I., and Kiss, G.: Hygroscopic properties of water-soluble matter and humic-like organics in atmospheric fine aerosol, Atmos. Chem. Phys., 4, 35-50, 2004.

Havers, N., Burba, P., Lambert, J., and Klockow, D.: Spectroscopic characterization of humic-like substances in airborne particulate matter, J. Atmos. Chem., 29, 45-54, 1998.

Hayase, K. and Tsubota, H.: Sedimentary humic acid and fulvic acid as surface active substances, Geochim. Cosmochim. Acta, 47, 947-952, 1983.

Hoffer, A., Kiss, G., Blazso, M., and Gelencser, A.: Chemical characterization of humic-like substances (HULIS) formed from a lignin-type precursor in model cloud water, Geophys. Res. Lett., 31, LO6115, doi:10.1029/2003GL018962, 2004.

Hung, H. M., Katrib, Y., and Martin, S. T.: Products and mechanisms of the reaction of oleic acid with ozone and nitrate radical, J. Phys. Chem. A, 109, 4517-4530, 2005.

Hur, J. and Schlautman, M. A.: Using selected operational descriptors to examine the heterogeneity within a bulk humic substance, Environ. Sci. Technol., 37, 880-887, 2003.

Iinuma, Y., Boge, O., Gnauk, T., and Herrmann, H.: Aerosolchamber study of the alpha-pinene $/ \mathrm{O}_{3}$ reaction: influence of particle acidity on aerosol yields and products, Atmos. Environ., 38, 761-773, 2004.

Ikeda, K., Arimura, R., Echigo, S., Shimizu, Y., Minear, R. A., and Matsui, S.: The fractionation/concentration of aquatic humic substances by the sequential membrane system and their characterization with mass spectrometry, Water Sci. Technol., 42, 383390, 2000.

Jang, M. S., Carroll, B., Chandramouli, B., and Kamens, R. M.: Particle growth by acid-catalyzed heterogeneous reactions of organic carbonyls on preexisting aerosols, Environ. Sci. Technol., 37, 3828-3837, 2003.

Jang, M. S., Czoschke, N. M., Lee, S., and Kamens, R. M.: Heterogeneous atmospheric aerosol production by acid-catalyzed particle-phase reactions, Science, 298, 814-817, 2002.

Jung, H. and Choi, H.: Effects of in situ ozonation on structural change of soil organic matter, Environ. Engineer. Sci., 20, 289299, 2003.

Kalberer, M., Paulsen, D., Sax, M., Steinbacher, M., Dommen, J., Prevot, A. S. H., Fisseha, R., Weingartner, E., Frankevich, V., Zenobi, R., and Baltensperger, U.: Identification of polymers as major components of atmospheric organic aerosols, Science, 303, 1659-1662, 2004.

Katrib, Y., Martin, S. T., Hung, H. M., Rudich, Y., Zhang, H. Z., Slowik, J. G., Davidovits, P., Jayne, J. T., and Worsnop, D. R.: Products and mechanisms of ozone reactions with oleic acid for aerosol particles having core-shell morphologies, J. Phys. Chem. A, 108, 6686-6695, 2004.

Kawahigashi, M. and Fujitake, N.: Surface-active properties of particle size fractions in two humic acids, Soil Sci. Plant Nutr., 44 497-505, 1998.

Kiss, G., Tombacz, E., and Hansson, H. C.: Surface tension effects of humic-like substances in the aqueous extract of troposphere fine aerosol, J. Atmos. Chem., 50, 279-294, doi:10.1007/s10874-005-5079-5, 2005.

Kiss, G., Tombacz, E., Varga, B., Alsberg, T., and Persson, L.: Estimation of the average molecular weight of humic-like substances isolated from fine atmospheric aerosol, Atmos. Environ., 37, 3783-3794, 2003.

Kiss, G., Varga, B., Galambos, I., and Ganszky, I.: Characterization of water-soluble organic matter isolated from atmospheric fine aerosol, J. Geophys. Res. - Atmos., 107, D21 8339, doi:10.1029/2001JD000603, 2002.

Kiss, G., Varga, B., Gelencser, A., Krivacsy, Z., Molnar, A., Alsberg, T., Persson, L., Hansson, H. C., and Facchini, M. C.: Characterisation of polar organic compounds in fog water, Atmos. Environ., 35, 2193-2200, 2001.

Krivacsy, Z., Gelencser, A., Kiss, G., Meszaros, E., Molnar, A., Hoffer, A., Meszaros, T., Sarvari, Z., Temesi, D., Varga, B., Baltensperger, U., Nyeki, S., and Weingartner, E.: Study on the chemical character of water soluble organic compounds in fine atmospheric aerosol at the Jungfraujoch, J. Atmos. Chem., 39, 235-259, 2001a.

Krivacsy, Z., Hoffer, A., Sarvari, Z., Temesi, D., Baltensperger, U., Nyeki, S., Weingartner, E., Kleefeld, S., and Jennings, S. G.: Role of organic and black carbon in the chemical composition of atmospheric aerosol at European background sites, Atmos. Environ., 35, 6231-6244, 2001b.

Krivacsy, Z., Kiss, G., Varga, B., Galambos, I., Sarvari, Z., Gelencser, A., Molnar, A., Fuzzi, S., Facchini, M. C., Zappoli, S., Andracchio, A., Alsberg, T., Hansson, H. C., and Persson, L.: Study of humic-like substances in fog and interstitial aerosol by size-exclusion chromatography and capillary electrophoresis, 
Atmos. Environ., 34, 4273-4281, 2000.

Krivacsy, Z., Molnar, A., Tarjanyi, E., Gelencser, A., Kiss, G., and Hlavay, J.: Investigation of inorganic ions and organic acids in atmospheric aerosol by capillary electrophoresis, J. Chromatog. A, 781, 223-231, 1997.

Kudryavtsev, A. V., Perminova, I. V., and Petrosyan, V. S.: Sizeexclusion chromatographic descriptors of humic substances, Analy. Chim. Acta, 407, 193-202, 2000.

Kujawinski, E. B., Hatcher, P. G., and Freitas, M. A.: Highresolution Fourier transform ion cyclotron resonance mass spectrometry of humic and fulvic acids: Improvements and comparisons, Anal. Chem., 74, 413-419, 2002.

Leenheer, J. A.: Comprehensive approach to preparative isolation and fractionation of dissolved organic carbon from natural waters and wastewaters, Environ. Sci. Technol., 15, 578-587, 1981.

Leenheer, J. A. and Croue, J. P.: Characterizing aquatic dissolved organic matter, Environ. Sci. Technol., 37, 18A-26A, 2003.

Leenheer, J. A., Croue, J. P., Benjamin, M., Korshin, G., Hwang, C., Bruchet, A., and Aiken, G.: Comprehensive isolation of natural organic matter from water for spectral characterization and reactivity testing, ACS Symposium Series 76, 68-83, 2000.

Leenheer, J. A., Rostad, C. E., Gates, P. M., Furlong, E. T., and Ferrer, I.: Molecular resolution and fragmentation of fulvic acid by electrospray ionization/multistage tandem mass spectrometry, Anal. Chem., 73, 1461-1471, 2001.

Li, S. M., Tang, J., Xue, H. S., and Toom-Sauntry, D.: Size distribution and estimated optical properties of carbonate, water soluble organic carbon, and sulfate in aerosols at a remote high altitude site in western China, Geophys. Res. Lett., 27, 1107-1110, 2000.

Likens, G. E. and Galloway, J. N.: The composition and deposition of organic carbon in precipitation, Tellus, 35B, 16-24, 1983.

Limbeck, A., Handler, M., Neuberger, B., Klatzer, B., and Puxbaum, H.: Carbon-specific analysis of humic-like substances in atmospheric aerosol and precipitation samples, Anal. Chem., 77, 7288-7293, 2005.

Limbeck, A., Kulmala, M., and Puxbaum, H.: Secondary organic aerosol formation in the atmosphere via heterogeneous reaction of gaseous isoprene on acidic particles, Geophys. Res. Lett., 30, 1996, 2003.

MacCarthy, P. and Rice, J. A.: Spectroscopic methods (other than NMR) for determining functionality in humic substances, in: Humic Substances in Soil, Sediments, and Water, edited by: Aiken, G. R., McKnight, D. M., Wershaw, R. L., and MacCarthy, P., Wiley-Interscience, New York, 527-560, 1985.

Malcolm, R. L. and MacCarthy, P.: Limitations in the use of commercial humic acids in water and soil research, Environ. Sci. Technol., 20, 904-911, 1986.

Marhaba, T. F. and Pu, Y.: Rapid delineation of humic and nonhumic organic matter fractions in water, J. Haz. Mat., 73, 221234, 2000

Marley, N. A., Gaffney, J. S., Orlandini, K. A., Picel, K. C., and Choppin, G. R.: Chemical characterization of size-fractionated humic and fulvic materials in aqueous samples, Sci. Total Environ., 113, 159-177, 1992.

Mayol-Bracero, O. L., Guyon, P., Graham, B., Roberts, G., Andreae, M. O., Decesari, S., Facchini, M. C., Fuzzi, S., and Artaxo, P.: Water-soluble organic compounds in biomass burning aerosols over Amazonia - 2. Apportionment of the chemical composition and importance of the polyacidic fraction, J. Geo- phys. Res.-Atmos., 107, D20 8091, doi:10.1029/2001JD000522, 2002.

Miles, C. J., Tuschall, J. R., and Brezonik, P. L.: Isolation of aquatic humus with diethylaminoethylcellulose, Anal. Chem., 55, 410 411, 1983.

Molot, L. A. and Dillon, P. J.: Photolytic regulation of dissolved organic carbon in northern lakes, Global Biogeochem. Cycles, 11, 357-365, 1997.

Molot, L. A., Hudson, J. J., Dillon, P. J., and Miller, S. A.: Effect of $\mathrm{pH}$ on photo-oxidation of dissolved organic carbon by hydroxyl radicals in a coloured, softwater stream, Aquatic Sci., 67, 189195, 2005.

Mukai, H. and Ambe, Y.: Characterization of a humic acid-like brown substance in airborne particulate matter and tentative identification of its origin, Atmos. Environ., 20, 813-819, 1986.

Myllykangas, T., Nissinen, T. K., Rantakokko, P., Martikainen, P. J., and Vartiainen, T.: Molecular size fractions of treated aquatic humus, Water Res., 36, 3045-3053, 2002.

Negre, M., Vindrola, D., Spera, S., Ferraris, L., and Gennari, M.: Effect of the chemical composition of soil humic acids on their viscosity, surface pressure, and morphology, Soil Sci., 167, 636651, 2002.

Nenes, A., Charlson, R. J., Facchini, M. C., Kulmala, M., Laaksonen, A., and Seinfeld, J. H.: Can chemical effects on cloud droplet number rival the first indirect effect? Geophys. Res. Lett., 29, 1848, doi:10.1029/2002GL015295, 2002.

Ohlenbusch, G., Hesse, S., and Frimmel, F. H.: Effects of ozone treatment on the soil organic matter on contaminated sites, Chemosphere, 37, 1557-1569, 1998.

Osburn, C. L., Morris, D. P., Thorn, K. A., and Moeller, R. E.: Chemical and optical changes in freshwater dissolved organic matter exposed to solar radiation, Biogeochem., 54, 251-278, 2001.

Perminova, I. V.: Size exclusion chromatography of humic substances: Complexities of data interpretation attributable to nonsize exclusion effects, Soil Sci., 164, 834-840, 1999.

Perminova, I. V., Frimmel, F. H., Kovalevskii, D. V., Abbt-Braun, G., Kudryavtsev, A. V., and Hesse, S.: Development of a predictive model for calculation of molecular weight of humic substances, Water Res., 32, 872-881, 1998.

Perminova, I. V., Frimmel, F. H., Kudryavtsev, A. V., Kulikova, N. A., Abbt-Braun, G., Hesse, S., and Petrosyan, V. S.: Molecular weight characteristics of humic substances from different environments as determined by size exclusion chromatography and their statistical evaluation, Environ. Sci. Technol., 37, 24772485, 2003.

Persson, L., Alsberg, T., Kiss, G., and Odham, G.: On-line sizeexclusion chromatography/electrospray ionisation mass spectrometry of aquatic humic and fulvic acids, Rapid. Commun. Mass Spectrom., 14, 286-292, 2000.

Pettersson, C., Ephraim, J., and Allard, B.: On the composition and properties of humic substances isolated from deep groundwater and surface waters, Org. Geochem., 21, 443-451, 1994.

Pettersson, C. and Rahm, L.: Changes in molecular weight of humic substances in the Gulf of Bothnia, Environmentl International, 22, 551-558, 1996.

Peuravuori, J., Monteiro, A., Eglite, L., and Pihlaja, K.: Comparative study for separation of aquatic humic-type organic constituents by DAX-8, PVP and DEAE sorbing solids and tangen- 
tial ultrafiltration: elemental composition, size-exclusion chromatography, UV-vis and FT-IR, Talanta, 65, 408-422, 2005.

Peuravuori, J. and Pihlaja, K.: Molecular size distribution and spectroscopic properties of aquatic humic substances, Analy. Chim. Acta, 337, 133-149, 1997.

Peuravuori, J. and Pihlaja, K.: Preliminary study of lake dissolved organic matter in light of nanoscale supramolecular assembly, Environ. Sci. Technol., 38, 5958-5967, 2004.

Peuravuori, J., Pihlaja, K., Trubetskaya, O., and Trubetskoj, O.: The effects of a strong disaggregating agent on SEC-PAGE of aquatic and soil humic matter, Int. J. Environ. Anal. Chem., 79, 217-228, 2001.

Pfeifer, T., Klaus, U., Hoffmann, R., and Spiteller, M.: Characterisation of humic substances using atmospheric pressure chemical ionisation and electrospray ionisation mass spectrometry combined with size-exclusion chromatography, J. Chromatog. A, 926, 151-159, 2001.

Piccolo, A.: The supramolecular structure of humic substances, Soil Sci., 166, 810-832, 2001.

Piccolo, A.: The supramolecular structure of humic substances: A novel understanding of humus chemistry and implications in soil science, in: Advances In Agronomy, 75, 57-134, 2002.

Piccolo, A. and Conte, P.: Molecular size of humic substances. Supramolecular associations versus macromolecular polymers, Adv. Environ. Res., 3, 508-521, 2000.

Piccolo, A., Conte, P., and Cozzolino, A.: Effects of mineral and monocarboxylic acids on the molecular association of dissolved humic substances, European J. Soil Sci., 50, 687-694, 1999.

Piccolo, A., Conte, P., and Cozzolino, A.: Chromatographic and spectrophotometric properties of dissolved humic substances compared with macromolecular polymers, Soil Sci., 166, 174 185, 2001

Piccolo, A., Conte, P., Spaccini, R., and Chiarella, M.: Effects of some dicarboxylic acids on the association of dissolved humic substances, Biol. Fertil. Soils, 37, 255-259, 2003.

Piccolo, A., Nardi, S., and Concheri, G.: Macromolecular changes of humic substances induced by interaction with organic acids, European J. Soil Sci., 47, 319-328, 1996a.

Piccolo, A., Nardi, S., and Concheri, G.: Micelle-like conformation of humic substances as revealed by size exclusion chromatography, Chemosphere, 33, 595-602, $1996 \mathrm{~b}$.

Piccolo, A. and Spiteller, M.: Electrospray ionization mass spectrometry of terrestrial humic substances and their size fractions, Anal. Bioanal. Chem., 377, 1047-1059, 2003.

Plancque, G., Amekraz, B., Moulin, V., Toulhoat, P., and Moulin, C.: Molecular structure of fulvic acids by electrospray with quadrupole time-of-flight mass spectrometry, Rapid. Commun. Mass Spectrom., 15, 827-835, 2001.

Pullin, M. J., Bertilsson, S., Goldstone, J. V., and Voelker, B. M.: Effects of sunlight and hydroxyl radical on dissolved organic matter: Bacterial growth efficiency and production of carboxylic acids and other substrates, Limnol. Oceanog., 49, 2011-2022, 2004.

Reemtsma, T. and These, A.: On-line coupling of size exclusion chromatography with electrospray ionization-tandem mass spectrometry for the analysis of aquatic fulvic and humic acids, Anal. Chem., 75, 1500-1507, 2003.

Rostad, C. E. and Leenheer, J. A.: Factors that affect molecular weight distribution of Suwannee river fulvic acid as de- termined by electrospray ionization/mass spectrometry, Analy. Chim. Acta, 523, 269-278, 2004.

Rudich, Y.: Laboratory perspectives on the chemical transformations of organic matter in atmospheric particles, Chem. Rev., 103, 5097-5124, 2003

Samburova, V., Kalberer, M., and Zenobi, R.: Characterization of high molecular weight compounds in urban atmospheric particles, Atmos. Chem. Phys., 5, 2163-2170, 2005a.

Samburova, V., Szidat, S., Hueglin, C., Fisseha, R., Baltensperger, U., Zenobi, R., and Kalberer, M.: Seasonal variation of high molecular weight compounds in the water-soluble organic fraction of urban aerosols, J. Geophys. Res. - Atmos., 110(D23), D23210, 2005b.

Sannigrahi, P., Sullivan, A. P., Weber, R. J., and Ingall, E. D.: Characterization of Water-Soluble Organic Carbon in Urban Atmospheric Aerosols Using Solid-State 13C NMR Spectroscopy, Environ. Sci. Technol., 2005.

Schafer, A. I., Mauch, R., Waite, T. D., and Fane, A. G.: Charge effects in the fractionation of natural organics using ultrafiltration, Environ. Sci. Technol., 36, 2572-2580, 2002.

Schwede-Thomas, S. B., Chin, Y. P., Dria, K. J., Hatcher, P., Kaiser, E., and Sulzberger, B.: Characterizing the properties of dissolved organic matter isolated by XAD and C-18 solid phase extraction and ultrafiltration, Aquatic Sci., 67, 61-71, 2005.

Simoneit, B. R. T.: Eolian particulates from oceanic and rural areas - their lipids fulvic and humic acids and residual carbon, in: Advances in Organic Geochemistry, edited by: Douglas, A. G. and Maxwell, J. R., Pergamon Press, Oxford, 343-352, 1980.

Simpson, A. J.: Determining the molecular weight, aggregation, structures and interactions of natural organic matter using diffusion ordered spectroscopy, Magnetic Resonance In Chemistry, 40, S72-S82, 2002

Slavinskaya, G. V. and Selemenev, V. F.: Ozonation of fulvic acids of natural waters in aqueous solutions, Russian J. Appl. Chem., 76, 1472-1475, 2003.

Spokes, L. J., Campos, M. and Jickells, T. D.: The role of organic matter in controlling copper speciation in precipitation, Atmos. Environ., 30, 3959-3966, 1996.

Stenson, A. C., Landing, W. M., Marshall, A. G., and Cooper, W. T.: Ionization and fragmentation of humic substances in electrospray ionization Fourier transform-ion cyclotron resonance mass spectrometry, Anal. Chem., 74, 4397-4409, 2002.

Stenson, A. C., Marshall, A. G., and Cooper, W. T.: Exact masses and chemical formulas of individual Suwannee River fulvic acids from ultrahigh resolution electrospray ionization Fourier transform ion cyclotron resonance mass spectra, Anal. Chem., 75, 1275-1284, 2003.

Stevenson, F. J.: Humus Chemistry: Genesis, Composition, Reactions, Wiley-Interscience, New York, 1982.

Stevenson, F. J.: Humus Chemistry (Genesis, Composition, Reactions), 2nd ed., John Wiley and Sons, New York, 1994.

Subbalakshmi, Y., Patti, A. F., Lee, G. S. H., and Hooper, M. A.: Structural characterisation of macromolecular organic material in air particulate matter using Py-GC-MS and solid state C-13NMR, J. Environ. Monitor., 2, 561-565, 2000.

Sutton, R. and Sposito, G.: Molecular structure in soil humic substances: The new view, Environ. Sci. Technol., 39, 9009-9015, 2005.

Svenningsson, B., Rissler, J., Swietlicki, E., Mircea, M., Bilde, M., 
Facchini, M. C., Decesari, S., Fuzzi, S., Zhou, J., Monster, J., and Rosenorn, T.: Hygroscopic growth and critical supersaturations for mixed aerosoll particles of inorganic and organic compounds of tmospheric relevance, Atmos. Chem. Phys. Discuss., 5, 28332877, 2005.

Swietlik, J., Dabrowska, A., Raczyk-Stanislawiak, U., and Nawrocki, J.: Reactivity of natural organic matter fractions with chlorine dioxide and ozone, Water Res., 38, 547-558, 2004.

Tabazadeh, A.: Organic aggregate formation in aerosols and its impact on the physicochemical properties of atmospheric particles, Atmos. Environ., 39, 5472-5480, 2005.

Tagliavini, E., Moretti, F., Decesari, S., Facchini, M. C., Fuzzi, S., and Maenhaut, W.: Functional group anaylsis by $\mathrm{H}$ $\mathrm{NMR} /$ chemical derivattization for the characterization of organic aerosol from the SMOCC field campaign, Atmos. Chem. Phys. Discuss., 5, 9447-9491, 2005.

These, A. and Reemtsma, T.: Limitations of electrospray ionization of fulvic and humic acids as visible from size exclusion chromatography with organic carbon and mass spectrometric detection, Anal. Chem., 75, 6275-6281, 2003.

These, A., Winkler, M., Thomas, C., and Reemtsma, T.: Determination of molecular formulas and structural regularities of low molecular weight fulvic acids by size-exclusion chromatography with electrospray ionization quadrupole time-of-flight mass spectrometry, Rapid. Commun. Mass Spectrom., 18, 1777-1786, 2004.

Thurman, E. M. and Malcolm, R. L.: Concentration and Fractionation of Hydrophobic Organic Acid Constitutents from Natural Waters by Liquid Chromatography, Geologic Survey WaterSupply Paper, Washington D.C., United States Government Printing Office, 16, 1979.

Thurman, E. M. and Malcolm, R. L.: Preparative isolation of aquatic humic substances, Environ. Sci. Technol., 15, 463-466, 1981.

Thurman, E. M., Malcolm, R. L., and Aiken, G. R.: Prediction of capacity factors for aqueous organic solutes adsorbed on a porous acrylic resin, Anal. Chem., 50, 775-779, 1978.
Tolocka, M. P., Jang, M., Ginter, J. M., Cox, F. J., Kamens, R. M., and Johnston, M. V.: Formation of oligomers in secondary organic aerosol, Environ. Sci. Technol., 38, 1428-1434, 2004.

Tombacz, E.: Colloidal properties of humic acids and spontaneous changes of their colloidal state under variable solution conditions, Soil Sci., 164, 814-824, 1999.

Varga, B., Kiss, G., Ganszky, I., Gelencser, A. and Krivacsy, Z.: Isolation of water-soluble organic matter from atmospheric aerosol, Talanta, 55, 561-572, 2001.

von Wandruszka, R.: The micellar model of humic acid: Evidence from pyrene fluorescence measurements, Soil Sci., 163, 921930, 1998.

Xiong, F., Croue, J. P., and Legube, B.: Long-term ozone consumption by aquatic fulvic acids acting as precursors of radical chain reactions, Environ. Sci. Technol., 26, 1059-1064, 1992.

Yates, L. M. and von Wandruszka, R.: Effects of $\mathrm{pH}$ and metals on the surface tension of aqueous humic materials, Soil Sci. Soc. Amer. J., 63, 1645-1649, 1999.

Yu, J. Z., Yang, H., Zhang, H. Y., and Lau, A. K. H.: Size distributions of water-soluble organic carbon in ambient aerosols and its size-resolved thermal characteristics, Atmos. Environ., 38, 1061-1071, 2004.

Zahardis, J., LaFranchi, B. W., and Petrucci, G. A.: Photoelectron resonance capture ionization-aerosol mass spectrometry of the ozonolysis products of oleic acid particles: Direct measure of higher molecular weight oxygenates, J. Geophys. Res.-Atmos., 110, D8 D08307, doi:10.1029/2004JD005336, 2005.

Zappoli, S., Andracchio, A., Fuzzi, S., Facchini, M. C., Gelencser, A., Kiss, G., Krivacsy, Z., Molnar, A., Meszaros, E., Hansson, H. C., Rosman, K., and Zebuhr, Y.: Inorganic, organic and macromolecular components of fine aerosol in different areas of Europe in relation to their water solubility, Atmos. Environ., 33, 27332743, 1999.

Ziemann, P. J.: Aerosol products, mechanisms, and kinetics of heterogeneous reactions of ozone with oleic acid in pure and mixed particles, Faraday Discuss., 130, 469-490, doi:10.1039/b417502f, 2005. 